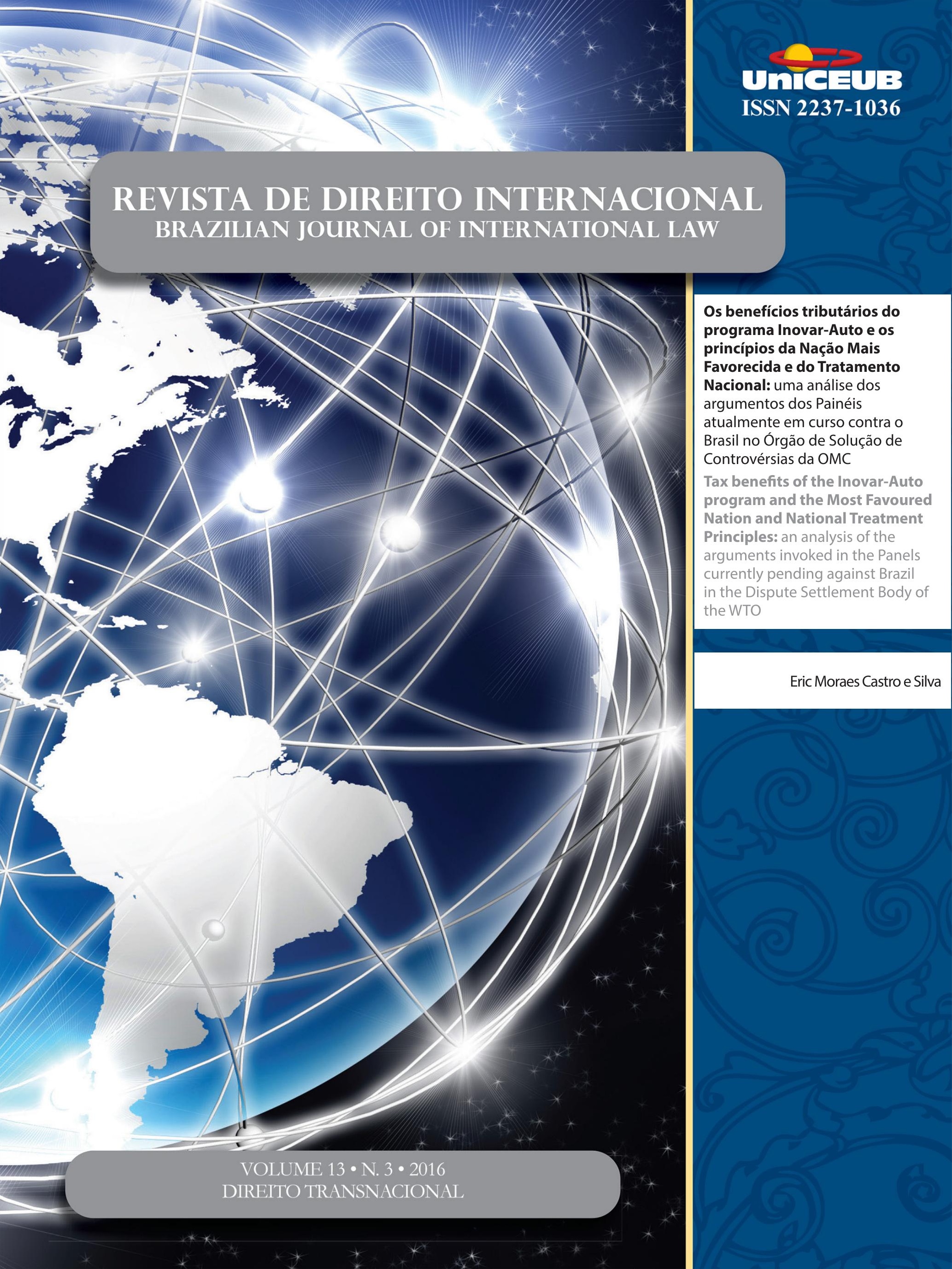


Crônicas da ATUALIdAde do direito internacional .................................................. 2

I. Dossiê Temático: Direito Transnacional .........................................................15

EDITORIAL: O Direito Transnacional - Circulação de normas e relações jurídicas transnacionais .......16 Priscila Pereira de Andrade

A emergênCia do direito transnacional ambiental .............................................18 Priscila Pereira de Andrade

Desafíos y RESPUESTAS TRANSNACIONALES FRENTE A LOS CRÍMENES AMBIENTALES ...............30 Rosmerlin Estupiñan-Silva

DiREITO TRANSNACIONAL E MUdANÇAS CLIMÁTICAS .50 Géraud de Lassus Saint-Geniès

Especies en movimiento: la Convención sobre el Comercio Internacional de Especies Amenazadas de Fauna y Flora Silvestres como espacio de “Encuentro” de discursos, ACTORES Y ESTRATEGIAS EN EL DERECHO AMBIENTAL TRASNACIONAL

María Valeria Berros e Dabel Leandro Franco

El carácter transnacional del Sistema comunitario de ECogestion « Eco-ManageMENT AND Audit SCHEME » (EMAS) DENTRo de LA UE y MÁs ALlÁ DE SUS Fronteras ......72 Adélie Pomade

O CONCEITO DE CONDUTA EMPRESARIAL RESPONSÁVEL À LUZ DOS ORDENAMENTOS JURÍDICOS BRASILEIRO, INTERNACIONAL E TRANSNACIONAL

Gabriel Webber Ziero

ARBITRAGEM NO DIREITO TRIBUTÁRIO INTERNACIONAL E NO DIREITO INTERNACIONAL DOS INVESTIMENTOS: UMA MANIFESTAÇÃO DO DIREITO TRANSNACIONAL

Vivian Daniele Rocha Gabriel 
O DIREITO TRIBUTÁRIO SOB UMA PERSPECTIVA TRANSNACIONAL

Franciele de Simas Estrela Borges

As Características do Direito Transnacional como Metodologia: Análise sob o enfoQue dos Aspectos Processuais da Arbitragem 126

Flávia Foz Mange

O DIREITO TRANSNACIONAL (“GLOBAL LAW") E A CRISE DE PARADIGMA DO ESTADO-CENTRISMO: É POSSÍVEL CONCEBER UMA ORDEM JURÍDICA TRANSNACIONAL? ...................................... 146

Luiza Nogueira Barbosa e Valesca Raizer Borges Moschen

TransPorte AÉREO E DIREITO TRANSNACIONAL: DA CONVERGÊNCIA À UNIFORMIDADE 160 Mickael R. Viglino

Outros Artigos. 175

O Fundo Monetário Internacional e a proteção dos direitos humanos: uma análise DO PROGRAMA DE CRESCIMENTO E REDUÇÃO DA POBREZA NO HAITI 177

Pablo Henrique Hubner de Lanna Costa e Carlos Alberto Simões de Tomaz

Um estranho no ninho? Padrões privados no Acordo de Barreiras Técnicas ao CoMÉRCIO DA OMC 192

Michelle Ratton Sanchez Badin e Marina Yoshimi Takitani

Os benefícios tributários do programa Inovar-Auto e os princípios da Nação Mais Favorecida e do Tratamento Nacional: uma análise dos argumentos dos Painéis atualmente em Curso contra o Brasil no Órgão de SoluÇão de Controvérsias da OMC . 211 Eric Moraes Castro e Silva

A ERA DA HUMANIDADE: REFLEXões PARA A HISTÓRIA DO DIREITO INTERNACIONAL 236 Henrique Weil Afonso

Precedentes vinculantes nos Estados Unidos da América e no direito brasileiro: Um ESTUDO COMPARADO 264

Patrícia Perrone Campos Mello 
IL DIRITTO AMBIENTALE SECONDO L'OTTICA DEL DIRITTO COSTITUZIONALE POSITIVO E LA RESPONSABILITÀ PER DANNI ALL'AMBIENTE NEL DIRITTO COMUNITARIO: LO STATO DELL'ARTE DEL DIRITTO AMBIENTALE COSTITUZIONALE E COMUNITARIO 287

Elcio Nacur Rezende

DA DESCONSIDERAÇÃo DA PERSONALIDADE JURÍDICA NAS RELAÇÕES CONSUMEIRISTAS BRASILEIRAS: ANÁLISE À LUZ DAS TEORIAS CLÁSSICAS

Daniel Amin Ferraz e Marcus Vinicius Silveira de Sá

ANALYSIS OF ADVANTAGES AND DISADVANTAGES OF FORUMS PRESCRIBED UNDER THE UNCLOS AND STATE PRACTICE: THE WAY AHEAD FOR INDIA ......................................................319

Vinai Kumar Singh

Do governo POR LEIS À governanÇA POR NúMERos: breve anÁlise do Trade in SERVICE AgreEMENT (TISA) ...............................................................................338 Jânia Maria Lopes Saldanha, Rafaela da Cruz Mello e Têmis Limberger

As DIRETIVAS EUROPEIAS COMO NORMA REGULADORA DO DIREITO ADMINISTRATIVO GLOBAL ..356 Alice Rocha da Silva e Ruth Maria Pereira dos Santos

O desenVolvimento da POlítica AGRícola COMUM dA UNião EUROPEIA 375 Tatiana de A. F. R. Cardoso Squeff

A imunidade de Jurisdição das organizaÇões internacionais FaCE AO Direito de aCESSO À JUSTIÇA 391

Fernanda Araújo Kallás e Caetano

O DIREITO INTERNACIONAL ENTRE O DEVER ÉTICO E A AÇÃo POLÍ́TICA: OS FUNDAMENTOS DE UM DEVER DE COOPERAÇÃO INTERNACIONAL NA FILOSOFIA POLÍTICA DE IMMANUEL KANT .405 Ademar Junior Pozzatti

EXTENSÃo E FRAGMENTAÇÃo NO CONTEXTO DA JURISDIÇÃO PENAL INTERNACIONAL .423 Marcus Vinícius Xavier de Oliveira

A DEFINiÇÃo JURÍdiCA DA "COMUNIDADE" .444 Nitish Monebhurrun, Michelle Lucas Cardoso Balbino, Fernanda Castelo Branco Araujo, Othon Pantoja, Míara Bogo Bruno e Cândida Dettenborn Nóbrega 
Comparative Study on Chinese Local Legislation of Science and Technology ProGRESS

LI Xiaoming e LI Yihan

O CONTROLE PENAL DO TRÁFICO DE PESSOAS: CONSTRUÇÃO JURÍDICA, INTERAÇÕES ORGANIZACIONAIS E COOPERAÇÃO INTERNACIONAL

Bruno Amaral Machado e Priscilla Brito Silva Vieira

Desativismo judicial: a extradição Battisti no Supremo Tribunal Federal .505 Francisco Rezek e Israel Paulino

A decisão norte-americana do Caso Myriad: novos paradigmas para a Proteção patenTÁRIA DO CÓDIGO GENÉTICO HUMANO E BIOTECNOLOGIA 514 José Carlos Vaz e Dias e Clarisse De La Cerda 


\title{
Os benefícios tributários do programa Inovar-Auto e os princípios da Nação Mais Favorecida e do Tratamento Nacional: uma análise dos argumentos dos Painéis atualmente em curso contra o Brasil no Órgão de Solução de Controvérsias da OMC*
}

\author{
Tax benefits of the Inovar-Auto program \\ and the Most Favoured Nation and National \\ Treatment Principles: an analysis of the \\ arguments invoked in the Panels currently \\ pending against Brazil in the Dispute \\ Settlement Body of the WTO
}

Eric Moraes Castro e Silva**

\section{Resumo}

O objetivo deste artigo é analisar a compatibilidade dos incentivos tributários previstos para o setor automobilístico brasileiro no programa Inovar-Auto com a interpretação jurisprudencial da Organização Mundial do Comércio (OMC) referente aos princípios do tratamento nacional e da nação mais favorecida. Tal matéria é, atualmente, objeto de painéis, propostos pela União Europeia (UE) e pelo Japão, contra o Brasil perante o Órgão de Solução de Controvérsias (OSC) daquela organização. O artigo adota a metodologia desenvolvida em vários julgados do GATT/OSC sobre questões tributárias, a qual consiste, inicialmente, em delimitar os incentivos e os requisitos para concessão dos benefícios previstos nas normas domésticas contestadas, o que, no caso, é feito pela análise para a concessão do crédito presumido e redução na importação do Imposto sobre Produtos Industrializados (IPI) previstos no Inovar-Auto. Em sucessivo, após registrar a importância que os julgados do OSC conferem àqueles dois princípios para fins de neutralidade concorrencial, o artigo demonstra que a evolução jurisprudencial da matéria estabeleceu verdadeiros "testes de consistência" para aferir a compatibilidade de normas tributárias domésticas com as obrigações estabelecidas nos artigos I e III do GATT', que disciplinam, respectivamente, os princípios da nação mais favorecida e do tratamento nacional. Os testes desenvolvidos pela jurisprudência do sistema multilateral do comércio são finalmente aplicados aos já delimitados benefícios tributários do Inovar-Auto, concluindo o artigo pela incompatibilidade do programa brasileiro com as obrigações assumidas perante a OMC.

Palavras-chave: Organização Mundial do Comércio. Inovar-Auto. Tratamento Nacional. Nação mais favorecida.

Recebido em 18/07/2016

Aprovado em 10/09/2016

** Professor de Direito Econômico, Financeiro e Tributário da UFPE; Doutor em Direito Econômico, Financeiro e Tributário pelo USP; Mestre em Direito pela Universidade de Cambridge. E-mail: eric@castroesilva.adv.br 


\section{Abstract}

The aim of this paper is to analyze the compatibility of the tax incentives granted by Brazil to its automotive industry under the Inovar-Auto program with the judicial interpretation of the World Trade Organization (WTO) regarding the national treatment and most favoured nation principles. This subject is currently under Panels, proposed by the European Union (EU) and Japan, against Brazil before the Dispute Settlement Body (DSB) of that organization. The article adopts the methodology developed in several cases of the GATT/ DSB on tax matters, such methodology initially delimitates the scope and requirements for granting the tax benefits provided for in the contested domestic measures, which in this case is made by the analysis and explanation for granting the presumed credit and reduction on imports of the Brazilian tax on industrialized products (IPI). In succession, after emphasizing the importance of those two principles for competitive neutrality purposes, the article demonstrates that case law established a true "consistency test" to assess the compatibility of domestic tax rules with the obligations laid down in Articles I and III of GATT, governing, respectively, the most favoured nation and national treatment principles. Those tests are finally applied to the tax benefits of the Inovar-Auto, concluding the article that the Brazilian program is not WTO compliant.

Keywords: World Trade Organization. Inovar-Auto. National treatment. Most Favoured Nacional.

\section{INTRODUÇÃo}

Após a crise financeira mundial de 2008, o Brasil introduziu uma séria de incentivos tributários para proteger a indústria local, sob o argumento da manutenção da competitividade dos produtores nacionais, com destaque para as medidas previstas no denominado "Plano Brasil Maior", anunciado em setembro de 2012 pelo Governo Federal.

Dentre tais incentivos tributários, destacam-se os previstos para o Programa de Incentivo à Inovação Tecnológica e Adensamento da Cadeia Produtiva de Veículos Automotores (Inovar-Auto), que estabelece reduções do Imposto sobre Produtos Industrializados (IPI) para montadoras de veículos já instaladas ou que pretendam se instalar no Brasil.

Em 19.12.2013 a União Europeia (UE) formalizou Pedido de Consulta perante a Organização Mundial do Comércio (OMC) para que o Brasil explicasse, dentre outras medidas, os incentivos tributários previstos no Inovar-Auto por suposta incompatibilidade daquelas medidas com os tratados que compõem a OMC.

Naquela Consulta, a UE ressaltava que os incentivos do Inovar-Auto, analisados, individualmente ou em conjunto com as outras medidas contestadas, dificultam a importação e fixam preferências e suporte a produtores domésticos e exportadores. Aduzia, ainda, que tais medidas, também, se caracterizam por revelar uma tributação mais onerosa para o bem importado comparativamente ao nacional, bem como por condicionar benefícios tributários ao uso de bens domésticos e conferir subsídios tributários contingentes à exportação. ${ }^{1}$

Insatisfeita com as informações brasileiras prestadas na fase de consulta, a UE, em 31.10.2014, requereu o estabelecimento de painel, o que foi deferido pelo Órgão de Solução de Controvérsias da OMC na reunião de 18.11.2014, tendo sido o Painel instalado em 17.12.2014 e seus membros indicados em 16.03.2014 pelo Diretor-Geral da OMC. ${ }^{2}$

Mesmo tendo o Japão aderido como terceiro interessado ao Pedido de Consulta formulado pela UE, assim como fizeram, também, outros doze países, o Japão entendeu por formalizar, em 02.07.2015, um pedido próprio de Consulta, ${ }^{3}$ ao qual aderiu a UE em 16.07.2015, que, também, resultou no estabelecimento de painel em 29.09.2015 perante o Órgão de Solução de Controvérsia da $\mathrm{OMC}^{4}$.

Apesar de compostos, os referidos painéis, até julho de 2016, ainda encontravam-se pendentes de decisões, que, necessariamente, deverão analisar os argumentos

1 Cf. Pedido de Consulta da União Europeia em Brazil: Certain Measures Concerning Taxation and Charges, WT/DS472/1, G/L/1061, G/SCM/D100/1, G/TRIMS/D/39, p. 1.

2 WTO. Dispute settlement. dispute DS472 Brazil: Certain Measures Concerning Taxation and Charges. Disponível em: <https://www. wto. org/english/tratop_e/dispu_e/cases_e/ds472_e.htm>. Acesso em: 18 mar. 2015.

3 Pedido de Consulta do Japão em Brazil: Certain Measures Concerning Taxation and Charges, WT/DS497/1, G/L/1119 G/ TRIMS/D/41, G/SCM/D108/1.

4 WTO. Dispute settlement. dispute DS472 Brazil: Certain Measures Concerning Taxation and Charges. Disponível em: $<$ https://www. wto. org/english/tratop_e/dispu_e/cases_e/ds472_e.htm>. Acesso em: 18 mar. 2015. 
de que, entre outras regras do sistema multilateral, os incentivos tributários do Inovar-Auto ofendem os princípios da nação mais favorecida e do tratamento nacional, previstos, respectivamente, nos artigos I e III do General Agreement on Tarifs and Trade (GATT).

Longe de querer se arvorar na competência dos painéis, o presente artigo pretende, apenas, analisar os incentivos brasileiros pela ótica da jurisprudência do sistema multilateral construída ao longo de vários julgados sobre matéria tributária para, sobre esses precedentes, opinar pela compatibilidade ou não do Inovar-Auto com as obrigações assumidas pelo Brasil perante o sistema multialteral do comércio.

Para tanto, adota-se aqui a mesma metodologia aplicada pelo GATT/OSC naqueles precedentes e que consiste em, inicialmente, identificar e delimitar os benefícios tributários nacionais para, posteriormente, submetê-los aos testes de consistência desenvolvidos pela jurisprudência da OMC em casos relativos aos princípios da nação mais favorecida e do tratamento nacional.

\section{Benefícios tributários do Inovar-Auto: Previsão e Requisitos}

Diante do expressivo deficit na balança comercial do setor automotivo registrado no ano de 2011 comparado ao saldo positivo obtido em 2006, o Governo Federal, alegando "[...] o preocupante quadro de perda de competitividade atualmente vivenciado pela indústria automobilística nacional, decorrente, em grade medida, do agravamento da situação econômica internacional", ${ }^{5}$ instituiu o Programa de Incentivo à Inovação Tecnológica e Adensamento da Cadeia Produtiva de Veículos Automotores, conhecido como Inovar-Auto.

O Programa foi introduzido pela MP n $\mathrm{n}^{\circ} 563 / 12$, convertida na Lei $n^{\circ} 12.715 / 2012$, cujos artigos 40 a 44 tratam especificamente do Inovar-Auto, sendo regulamentado pelo Decreto n ${ }^{\circ}$ 7. 819/2012 e várias Portarias do Ministério do Desenvolvimento, Indústria e Comércio Exterior (MDIC).

As medidas entraram em vigor em janeiro de 2013 com vigência até dezembro de 2017 e "[...] têm como objetivo apoiar o desenvolvimento tecnológico, a ino-

5 Parágrafo 46 da Exposição de Motivos da Medida Provisória n ${ }^{\circ}$ $563 / 12$, de 3/04/2012. vação, a segurança, a proteção ao meio ambiente, a eficiência energética e a qualidade dos veículos e das autopeças". ${ }^{6}$

O Inovar-Auto tem como beneficiários três contribuintes do IPI, quais sejam: os que produzem veículos no Brasil; os que não produzem, mas importam e comercializam veículos no mercado interno; e os contribuintes que tenham projeto de investimentos aprovado para instalação ou ampliação, no Brasil, de fábrica daqueles veículos.

Os benefícios tributários do Inovar-Auto consistem em crédito presumido do IPI na fabricação e na importação de automóveis, bem como na redução da alíquota ou suspensão do IPI na importação de veículos, desde que os beneficiários previamente se habilitem no MDIC, sendo a habilitação concedida pelo prazo de doze meses, renovável até 31.12.2017, prazo final de vigência do Programa.

O Decreto n ${ }^{\circ}$ 7. 819/2012 estabelece condições gerais e específicas para a habilitação pelos três possíveis beneficiários do Inovar-Auto. As condições gerais exigem a regularidade fiscal do contribuinte e o compromisso de atingir níveis mínimos de eficiência energética em relação aos produtos comercializados no Brasil.

As condições específicas para os contribuintes que produzem veículos no Brasil exigem que a empresa realize uma quantidade mínima de atividades fabris e de infraestrutura de engenharia em pelo menos $80 \%$ dos veículos aqui fabricados. Tais atividades são descritas no anexo III do Regulamento e compreendem, por exemplo, estampagem, solda, tratamento anticorrosivo e pintura, injeção de plástico, fabricação de motor, fabricação de caixa de câmbio e transmissão, entre outras atividades.

$\mathrm{O}$ inciso I do art. $7^{\circ}$ do Decreto regulamentar estabelece um cronograma fixando a quantidade mínima daquelas atividades fabris e de infraestrutura que os contribuintes já instalados no país devem realizar ao longo dos anos. Fabricantes de veículos comerciais leves, por exemplo, deveriam realizar de oito a doze daquelas atividades em 2013, nove a doze em 2014/15 e de dez a doze em 2017.

Além daquelas atividades fabris e de infraestrutura, os contribuintes que já produzem no Brasil, também,

$6{\text { Art. } 1^{\circ} \text { do Decreto n }}^{\circ} 7.819 / 12$. 
são obrigados a realizar no mínimo dois dos seguintes requisitos estabelecidos no art. $7^{\circ}$ do Decreto $n^{\circ} 7$. 819/12:

$$
\begin{aligned}
& {[\ldots] \text { art. } 7^{\circ}[\ldots] .} \\
& \text { I - omissis. } \\
& \text { II - realizar, no País, dispêndios em pesquisa e } \\
& \text { desenvolvimento correspondentes, no mínimo, aos } \\
& \text { percentuais, a seguir indicados [0,15\% em 2013; 0, } \\
& 30 \% \text { em 2014; 0, 50\% de } 2015 \text { a 2017], incidentes } \\
& \text { sobre a receita bruta total de venda de bens e } \\
& \text { serviços, excluídos os impostos e contribuições } \\
& \text { incidentes sobre a venda. }
\end{aligned}
$$

III - realizar, no País, dispêndios em engenharia, tecnologia industrial básica e capacitação, de fornecedores correspondentes, no mínimo, aos percentuais, a seguir indicados $[0,5 \%$ em 2013; 0, 75\% em 2014 e 1\% em 2015/2017], incidentes sobre a receita bruta total de venda de bens e serviços, excluídos os impostos e contribuições incidentes sobre a venda.

IV - aderir a Programa de Etiquetagem Veicular definido pelo Ministério do Desenvolvimento, Indústria e Comércio Exterior e estabelecido pelo Instituto Nacional de Metrologia, Qualidade e Tecnologia-INMETRO, com eventual participação de outras entidades públicas, com os seguintes percentuais mínimos dos modelos [36\% em 2013; 49\% em 2014; 64\% em 2015; 81\% em 2016 e 100\% em 2017], conforme definido no Programa de Etiquetagem Veicular do INMETRO, de produtos classificados nos códigos TIPI relacionados no Anexo I, comercializados pela empresa, a serem etiquetados no âmbito do referido Programa. ${ }^{8}$

Para os contribuintes que não produzem no Brasil, mas aqui comercializam veículos, é exigida a satisfação dos três requisitos acima transcritos para que possam habilitar-se ao Programa.

Por fim, os contribuintes que pretendem a instalação de fábrica ou de nova planta ou projeto industrial no país deverão apresentar projeto que satisfaça aos termos estabelecidos pelo MDIC e aos critérios para a determinação da capacidade anual de produção.?

Uma vez habilitados, ${ }^{10}$ os contribuintes passam a fazer jus aos benefícios tributários instituídos pelo Programa. O primeiro deles é o crédito presumido do IPI,

7 Regulamentação complementar pela Portaria Interministerial MDIC/MCT n ${ }^{\circ}$ 772, de 12.08.2013.

8 Regulamentação complementar pela Portaria MDIC n ${ }^{\circ} 113$ de 15.04.2013.

9 Regulamentação complementar pela Portaria MDIC no 297 de 30.09.2013.

10 Verificar relação de empresas habilitadas na Portaria MDIC $n^{\circ}$ 106, de 11.04.2013. que pode ser concedido em duas operações distintas: na fabricação local e/ou na importação de veículos.

$\mathrm{Na}$ fabricação local dos veículos, o crédito presumido do IPI será apurado com base nos dispêndios realizados em cada mês relativos a: insumos estratégicos, ferramentaria, pesquisa, desenvolvimento tecnológico, inovação tecnológica, recolhimento ao Fundo Nacional de Desenvolvimento Científico e Tecnológico (FNDCT), capacitação de fornecedores e engenharia e tecnologia industrial básica.

O crédito presumido sobre os dispêndios incorridos com insumos estratégicos e ferramentaria ${ }^{11}$ é apurado com base na multiplicação dos valores dos dispêndios realizados com os fatores estabelecidos no Decreto, que variam de acordo com a espécie do veículo e o respectivo ano da produção. Para automóveis e comerciais leves, por exemplo, os fatores são 1, 30 em 2013; 1, 25 em 2014; 1, 15 em 2015; 1, 10 em 2016; e 1, 00 em 2017. Para caminhões e chassis com motor, o referido fator varia de acordo com a receita líquida de vendas da empresa nos segmentos de caminhões pesados, semipesados, chassis com motor, caminhões semileves, leves e médios.

Em relação aos insumos estratégicos e ferramentaria, o art. 41-A da Lei $n^{\circ} 12.715 / 2012$ obriga que fornecedores de tais produtos informem aos clientes (i. e os contribuintes habilitados no Inovar-Auto que produzem localmente) os valores e demais características dos produtos fornecidos nos termos, limites e condições definidos pelo MDIC, sob pena de multa.

O $\int 6^{\circ}$ do art. 32-B do Decreto $n^{\circ} 7.819 / 12$, a seu turno, impede que o contribuinte habilitado no Inovar-Auto apure crédito presumido do IPI nas aquisições de insumos estratégicos e ferramentaria se os fornecedores não prestarem aquelas informações exigidas pelo art. 41-A da Lei e que foram regulamentadas pela Portaria MDIC n ${ }^{\circ} 257 / 14$.

Consequentemente, o crédito presumido do IPI apurado com base nos dispêndios com insumos estratégicos e ferramentaria induz a que toda a cadeia produtiva do setor automotivo seja realizada localmente com insumos nacionais, concretizando-se, assim, o proclamado objetivo do "adensamento" da cadeia produtiva de veículos automotores.

11 Para definição de insumos estratégicos e ferramentaria cf. artigos $1^{\circ}$ e $2^{\circ}$ da Portaria MDIC no 257, de 23.09.2014. 
Apurado o crédito presumido com base nos dispêndios com insumos estratégicos e ferramentaria, o benefício poderá ser utilizado para o pagamento do IPI devido na saída dos veículos fabricados ou comercializados no país. Contudo, a utilização nessas duas hipóteses fica limitada ao valor correspondente ao que resultaria da aplicação de $30 \%$ sobre a base de cálculo prevista na legislação do IPI.

Na hipótese de, em razão da limitação acima, restar saldo do crédito presumido, este poderá ser utilizado para o pagamento do IPI devido na importação de veículos feita pelo mesmo contribuinte. Ainda assim, duas limitações adicionais aplicam-se: o valor do crédito presumido a ser utilizado na importação fica limitado ao valor correspondente ao que resultaria da aplicação de 30\% sobre a base de cálculo prevista na legislação do IPI e a utilização estará limitada a 4. 800 veículos por ano.

O crédito presumido apurado sobre dispêndios incorridos com pesquisa, desenvolvimento tecnológico, inovação tecnológica e recolhimento ao Fundo Nacional de Desenvolvimento Científico e Tecnológico (FNDCT) corresponde a 50\% desses dispêndios, limitados ao valor que corresponder à aplicação de $2 \%$ da receita bruta total de vendas de bens e serviços do segundo mês anterior ao da apuração do crédito, excluídos impostos e contribuições incidentes sobre a venda.

O crédito presumido sobre dispêndios incorridos com recolhimento ao FNDCT, capacitação de fornecedores e engenharia e tecnologia industrial básica corresponde a $50 \%$ do valor dos dispêndios que excederem a $75 \%$, limitados a $2,75 \%$ da receita bruta total de venda de bens e serviços do segundo mês anterior ao do mês de apuração do crédito, excluídos os impostos e contribuições incidentes sobre a venda.

O crédito presumido relativo à pesquisa, desenvolvimento tecnológico, inovação tecnológica, recolhimento ao FNDCT, capacitação de fornecedores e engenharia e tecnologia industrial básica deve, primeiramente, ser utilizado para a dedução do valor do IPI devido nas operações no mercado interno da matriz do contribuinte. Havendo saldo, este poderá ser transferido para as filiais do contribuinte ou ser solicitado o ressarcimento ou compensação com outros tributos federais.

A segunda modalidade de crédito presumido do IPI, apurado na importação de veículos, é concedida, exclusivamente, para empresas que tenham projeto de insta- lação de fábrica ou de nova planta ou projeto industrial no Brasil. Assim, tais empresas poderão apurar crédito presumido do imposto tanto em relação à produção nas já existentes unidades fabris quanto em relação à importação de veículos em razão da aprovação de um novo projeto.

Para os importadores que se comprometem a implantar ou ampliar uma fábrica, o Inovar-Auto garante crédito presumido do IPI correspondente ao resultado da aplicação da alíquota de 30\% sobre a base de cálculo do mesmo imposto na saída dos produtos do estabelecimento importador.

O crédito presumido na importação, contudo, é vinculado ao cumprimento do cronograma físico-financeiro constante do projeto previamente aprovado no MDIC, de acordo com a Portaria no 297/13, cujo Anexo VI também exige atividades fabris e de infraestrutura de engenharia desenvolvidas no Brasil, com produtos intermediários fabricados aqui.

Além disso, a quantidade de veículos produzidos pelo contribuinte, expressa no projeto de nova fábrica, também serve como limitadora do número de veículos que podem ser importados com o gozo do crédito presumido do IPI.

Isso porque a quantidade de veículos importados no ano-calendário, que dará direito à apuração de crédito presumido, fica limitada a $25 \%$ da capacidade de produção anual prevista no projeto de investimento aprovado. Assim, caso o projeto indique a produção anual de 100.000 veículos, o contribuinte poderá importar até 25.000 veículos com o benefício do crédito presumido do IPI.

Registre-se, ainda, que o crédito presumido na importação só vigora por 24 meses contados da primeira habilitação. Decorrido esse prazo, o contribuinte deixará de apurar o crédito presumido na importação, restando-lhe a possibilidade de apurar crédito presumido na fabricação local do veículo.

O crédito presumido apurado na importação de veículos poderá ser utilizado para pagamento do IPI devido na saída do contribuinte importador, previamente habilitado, observados os seguintes limitadores: o limite de 1/48 da capacidade de produção anual prevista no projeto multiplicado pelo número de meses restantes do ano, o prazo de 24 meses contados da habilitação e apenas de veículos constantes do projeto de investimentos aprovado. 
Ainda havendo saldo do crédito presumido apurado na importação, este, somente, poderá ser aproveitado na saída de veículos fabricados pela empresa habilitada, a partir do início da comercialização dos veículos objeto do projeto, até o montante correspondente a 35\% do saldo devedor apurado a cada período de apuração do IPI.

Outro benefício tributário previsto no Inovar-Auto é a redução da alíquota do IPI em 30\% na importação dos veículos descritos no anexo I do Decreto e que sejam oriundos do México, Argentina, Paraguai e Uruguai. Tal redução. Contudo, só se concede para empresa habilitada que já produz no Brasil ou que tenha projeto de ampliação ou implantação de fábrica aprovado no MDIC. Em outras palavras, empresas que não produzem, mas apenas comercializam veículos importados não têm direito à redução.

Uma segunda hipótese de redução de 30\% da alíquota do IPI na importação, nesse caso podendo ser usufruída, também, por empresa que, apenas, comercializa veículos no país, dá-se quando os veículos importados são oriundos do Uruguai; ou quando importados por encomenda ou por conta e ordem de empresa habilitada até o limite da medida aritmética da quantidade de veículos importados pela empresa nos anos de 2009 a 2011 ou até 4.800 veículos (o que for menor); ou quando fabricados por empresas que apresentem volume de produção anual inferior a 1.500 unidades e faturamento anual não superior a 90 milhões de reais; ou, por fim, quando caracterizados como quadricíclos ou tricíclos.

As importações feitas com as alíquotas do IPI reduzidas em 30\% não geram direito à apuração do crédito presumido do imposto, exceto as que excederem limites ou restrições quantitativas eventualmente existentes nos acordos neles referidos, desde que realizadas por empresas habilitadas. Por fim, o Inovar-Auto ainda concede a suspensão do IPI sobre os veículos importados que dão direito ao crédito presumido, mas apenas na hipótese em que os veículos sejam destinados à comercialização.

É em relação aos requisitos da habilitação no Programa e à forma de apuração e utilização dos benefícios tributários acima descritos que a UE demonstra receio de possível inadequação do Inovar-Auto com os princípios e regras da OMC.

Nesse sentido, a Europa expressou no Pedido de Consulta as seguintes observações sobre possíveis inconsistências do Inovar-Auto com as normas da OMC:
O montante do crédito tributário para as empresas participantes 'habilitadas' depende do montante e da natureza das despesas de cada beneficiário incorridas no Brasil. De longe, o item mais importante para efeitos de acúmulo de créditos tributários gastos no Brasil com "insumos e ferramentas estratégicas". Consequentemente, os distribuidores de veículos importados sem atividades de fabricação no Brasil não podem ganhar qualquer crédito fiscal considerável para compensar o IPI sobre bens importados. As condições relativas a P\&D e despesas com tecnologias também são baseados em um critério que penaliza os bens importados. Além disso, o sistema é orientado para favorecer a utilização de componentes fabricados no Brasil por fabricantes domésticos. Além disso, as condições para utilização dos créditos tributários acumulados pelos fabricantes habilitados limitam a possibilidade de compensar o IPI devido sobre as mercadorias importadas. Finalmente, o INOVARAUTO parece conceder certos benefícios fiscais a mercadorias originárias de um número limitado de outros países, incluindo o Mercosul e países não membros do Mercosul, sem estender esses benefícios a outros membros da OMC. ${ }^{12}$

Para Europa e Japão, as referidas práticas podem estar em desacordo com o art. I, $\int 1^{\circ}$, e art. III, $\int 2^{\circ}, \int 4^{\circ}$ e $\int 5^{\circ}$, do GATT, que disciplinam, respectivamente, os princípios da nação mais favorecida e do tratamento nacional, que passam a ser analisados pela metodologia da jurisprudência do Órgão de Solução de Controvérsias da OMC nos tópicos a seguir.

\section{Princí́pio da Nação Mais Favorecida: INOVAR-AUTO E O ART. I DO GATT}

\author{
Conforme estabelecido pelo Órgão de Apelação da
}

12 Trad. livre do autor. No original: "The amount of the tax credit for 'accredited' participating companies depends on the amount and the nature of each participant's expenditures in Brazil. By far the most important item for the purposes of accruing tax credits are expenditures in Brazil on 'strategic inputs and tools'. Therefore, distributors of imported vehicles without manufacturing activities in Brazil cannot earn any sizeable tax credit to offset the IPI tax on imported goods. The conditions pertaining to $\mathrm{R} \& \mathrm{D}$ and technological expenditure are also based on a criterion that penalises imported goods. In addition, the system is geared to favour the use of Brazilian-made components by domestic manufacturers. Moreover, the conditions for use of the tax credits earned by manufacturing participants limit the possibilities to offset the IPI tax due on imported goods. Finally, INOVAR-AUTO appears to grant certain tax benefits to goods originating in a limited number of other countries, including Mercosur and non-Mercosur countries, without those benefits being extended to other WTO Members". Cf. Pedido de Consulta da União Europeia em Brazil: Certain Measures Concerning Taxation and Charges, WT/DS472/1, G/L/1061, G/SCM/D100/1, G/TRIMS/D/39, p. 2. 
OMC no caso Canada - Autos, ${ }^{13}$ a finalidade da cláusula da nação mais favorecida no GATT é proibir a discriminação entre produtos similares que se originam em diferentes países ou se destinam a eles, a qual, também, serve como incentivo para que as concessões negociadas, reciprocamente, sejam estendidas para terceiros. ${ }^{14}$

Assim, pelo princípio da nação mais favorecida (MFN, em inglês), qualquer benefício concedido por um país a outro deve ser estendido, automaticamente, para todos os demais países-membros do sistema comercial internacional, independentemente de esses terceiros países terem participado das negociações que resultaram no estabelecimento do benefício.

Consequentemente, a regra da nação mais favorecida protege a expectativa dos membros da OMC de neutralidade concorrencial, por assegurar igualdade de oportunidade de competição, como reiterou com base em prévios julgados o Órgão de Apelação no caso EC - Seal Products. ${ }^{15}$

Por ser “[...] um princípio que há muito é uma pedra angular do GATT e é um dos pilares do sistema OMC" ${ }^{16}$ é possível encontrar ao longo do texto do GATT várias obrigações que estabelecem o dever de extensão automática de benefícios negociados bilateralmente para terceiros, como, por exemplo, a regulamentação relativa a misturas (art. III, $\int 7^{\circ}$ ), trânsito de bens

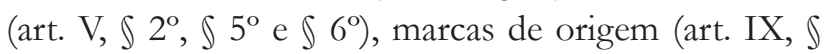
$1^{\circ}$ ), restrições quantitativas (art. XIII, $\mathbb{S} 1^{\circ}$ ), entre outras.

Para fins tributários, a obrigação do tratamento da nação mais favorecida vem disposta no art. I, $\int 1^{\circ}$ do GATT, que obriga que os benefícios tributários confe-

13 Cf. JOHNSON, Jon R. The WTO Decision - MFN, National Treatment, TRIMS and Export Subsidies. In: IRISH, Maureen (Org.). The auto pact: investment, labour and the WTO. Haia: Kluewer Law International, p. 78-109.

14 Cf. WTO. Relatório do Órgão de Apelação em Canada: Certain Measures Affecting the Automotive Industry, WT/DS139/AB/R, WT/DS142/AB/R e Relatório do Painel em Canada: Certain Measures Affecting the Automotive Industry, WT/DS139/R, WT/DS142/R. Disponível em: <https://www.wto.org/english/tratop_e/dispu_e/ dispu_status_e.htm>. Acesso em: 11 jul. 2016.p. 27.

15 Cf. Relatório do Órgão de Apelação em European Communities: Measures Prohibiting the Importation and Marketing of Seal Products Industry, WT/DS400/AB/R, WT/DS401/AB/R, parágrafo 5.87. p. 120.

16 Trad. livre do autor. No original: "[a] principle that has long been a cornerstone of the GATT and is one of the pillars of the WTO trading system". Relatório do Órgão de Apelação em Canada: Certain Measures Affecting the Automotive Industry, WT/DS139/ AB/R, WT/DS142/AB/R, parágrafo 69. p. 23. ridos para a importação de determinado país devem ser imediata e incondicionalmente ${ }^{17}$ estendidos a todos os membros, nos seguintes termos:

1. Qualquer vantagem, favor, imunidade ou privilégio concedido por uma Parte Contratante em relação a um produto originário de ou destinado a qualquer outro país, será imediata e incondicionalmente estendido ao produtor similar, originário do território de cada uma das outras Partes Contratantes ou ao mesmo destinado. Este dispositivo se refere aos direitos aduaneiros e encargos de toda a natureza que gravem a importação ou a exportação, ou a elas se relacionem, aos que recaiam sobre as transferências internacionais de fundos para pagamento de importações e exportações, digam respeito ao método de arrecadação desses direitos e encargos ou ao conjunto de regulamentos ou formalidades estabelecidos em conexão com a importação e exportação bem como aos assuntos incluídos nos $\iint 2$ e 4 do art. $3 .^{18}$

Ao citar medidas tarifárias e cobranças de qualquer tributo (customs duties and charges of any kind), o referido dispositivo alcança não apenas as medidas tarifárias negociadas e fixadas nas Listas de Concessões, mas também qualquer forma de tributação interna que possa distorcer a concorrência entre produtos de diversas origens, como demonstrado no julgamento Indonesia Autos, no qual a Indonésia conferia isenção de tarifas adianeiras e de tributos internos sobre vendas, apenas, para veículos importados da Coreia do Sul. ${ }^{19}$

17 Para registro histórico, importa ressaltar que a modalidade condicionada do tratamento da nação mais favorecida, isto é, o estabelecimento de determinadas condições para que terceiros países gozem das concessões comerciais das quais não negociaram, era a regra até o início do século XX, por veemente exigência dos Estados Unidos. Apenas, em 1923, os Estados Unidos passaram a apoiar o tratamento da nação mais favorecida na sua modalidade incondicionada, o que foi essencial para a multilateralização do sistema comercial, já que amplia exponencialmente as regras do sistema pela inclusão de países que restaram ausentes das rodadas de negociação. Cf. JACKSON, J. H.; DAVEY, W. J.; SKYKES, A. J. Legal problems of international economic relations, cases, materials and text. 3. ed. Saint Paul: West Group, 1995.

18 Versão oficial em inglês: "1. With respect to customs duties and charges of any kind imposed on or in connection with importation or exportation or imposed on the international transfer of payments for imports or exports, and with respect to the method of levying such duties and charges, and with respect to all rules and formalities in connection with importation and exportation, and with respect to all matters referred to in paragraphs 2 and 4 of Article III, any advantage, favour, privilege or immunity granted by any contracting party to any product originating in or destined for any other country shall be accorded immediately and unconditionally to the like product originating in or destined for the territories of all other contracting parties".

19 Cf. WTO. Relatório do Painel em Indonesia: Certain Measures Af- 
Baseado no caso EC-Bananas III, o Painel do caso Indonesia - Autos decidiu que há violação da regra MFN quando uma vantagem tributária concedida a um membro não é estendida incondicionalmente para produtos similares de todos os demais membros da OMC:

De acordo com esta análise, nós devemos primeiro
examinar se o incentivo [concedido] pelo tributo
e pela tarifa aduaneira são vantagens das espécies
regulamentadas pelo art. 1 . Segundo, nós deveremos
decidir se as vantagens são oferecidas (i) para todos
os produtos e (ii) incondicionalmente. ${ }^{20}$

Com base na evolução jurisprudencial acima descrita, os julgados do OSC estabeleceram um teste de consistência entre a tributação doméstica e a regra MFN, que pode, assim, ser resumido: a) define-se se os benefícios concedidos pela tributação doméstica são "vantagens" para fins do art. I do GATT; e b) se tais "vantagens" são oferecidas a todos os produtos similares, independentemente da origem, de forma incondicional.

Em relação a definir se os benefícios tributários constituem "vantagens", o Painel do caso Indonesia - Autos fundamentou-se na referência que o art. I, $\int 1^{\circ}$ faz ao art. III, $\int 2^{\circ}$ e $\int 4^{\circ}$ do GATT, para concluir que as medidas tributárias que ofendem o tratamento nacional podem, também, ofender a cláusula da nação mais favorecida. ${ }^{21}$

Assim, normas tributárias que reduzem a base de cálculo, a alíquota ou estabelecem formas de cobrança dos tributos de modo mais favorável a produtos oriundos de apenas um país, ${ }^{22}$ mas não as estendem aos demais membros do sistema multilateral, devem ser tidas como ofensivas ao tratamento da nação mais favorecida.

A definição do que sejam produtos similares (like

fecting the Automotive Industry, WT/DS54/R, WT/DS55/R, WT/DS59/R, WT/DS64/R. Disponível em: <https://www.wto. org/english/tratop_e/dispu_e/dispu_status_e.htm>. Acesso em: 11 jul. 2016. parágrafo 14.139. p. 355 .

20 Trad. livre do autor. No original: "Following this analysis, we shall first examine whether the tax and customs duty benefits are advantages of the types covered by Article 1. Second, we shall decide whether the advantages are offered (i) to all like products and (ii) unconditionally". Relatório do Painel em Indonesia: Certain Measures Affecting the Automotive Industry, WT/DS54/R, WT/DS55/R, WT/DS59/R, WT/DS64/R. Disponível em: <https://www.wto. org/english/tratop_e/dispu_e/dispu_status_e.htm>. Acesso em: 11 jul. 2016. parágrafo 14.138, p. 355.

21 Cf. Relatório do Painel em Indonesia: Certain Measures Affecting the Automotive Industry, WT/DS54/R, WT/DS55/R, WT/ DS59/R, WT/DS64/R. Disponível em: <https://www.wto.org/ english/tratop_e/dispu_e/dispu_status_e.htm >. Acesso em: 11 jul. 2016. parágrafo 14.139. p. 355.

22 Cf. item 4. products) para fins do MFN, também, se vale do entendimento jurisprudencial fixado no art. III, $\ 2^{\circ}$, primeira sentença, que tem nessa classe de produtos um dos requisitos para a ofensa ao tratamento nacional. ${ }^{23}$ Nesse sentido, a jurisprudência do OSC decide, de forma reiterada, que a distinção de produtos feita apenas com base na origem de um deles não é suficiente para torná-los diferentes para fins de competição no mercado internacional. ${ }^{24}$

Por fim, a vantagem tributária não pode ser condicionada, de fato ou de direito, a apenas um ou poucos membros da OMC. Nesse sentido, interessante as medidas tributárias analisadas no caso Canada - Autos, entre elas um tratado bilateral com os Estados Unidos.

Ao decidir o caso, o Painel asseverou que as medidas tributárias canadenses tinham como consequência prática o fato de que a expressiva maioria dos produtos importados pelo Canadá, com os benefícios tributários questionados, advinham, majoritariamente, dos Estados Unidos, o que era suficiente para comprovar a violação de fato à nação mais favorecida. ${ }^{25}$

Ainda em relação à impossibilidade de exigência de condicionantes para que terceiros países usufruam dos benefícios tributários conferidos a determinado membro, importante o caso levado formalmente ao GATT em 1952 referente ao regime tributário belga denominado Allocations Familiales. Pelo regime belga, havia tributação sobre bens cuja receita era destinada a financiar benefícios sociais para as famílias locais. O mesmo tributo era cobrado sobre produtos importados, condicionado ao fato de que, no país exportador, não houvesse tributação semelhante à belga. Consequentemente, produtos similares importados recebiam tratamento tributário diverso dependendo do sistema tributário do país exportador, o que foi rechaçado pelo GATT, que não aceita condicionantes para a extensão das concessões alcança-

23 Cf. WTO. Relatório do Painel em Indonesia: Certain Measures Affecting the Automotive Industry, WT/DS54/R, WT/DS55/R, WT/DS59/R, WT/DS64/R. Disponível em: <https://www.wto. org/english/tratop_e/dispu_e/dispu_status_e.htm>. Acesso em: 11 jul. 2016. parágrafo 7.356, p. 163.

24 Cf. item 4.

25 Cf. WTO. Relatório do Órgão de Apelação em Canada: Certain Measures Affecting the Automotive Industry, WT/DS139/AB/R, WT/DS142/AB/R e Relatório do Painel em Canada: Certain Measures Affecting the Automotive Industry, WT/DS139/R, WT/DS142/R. Disponível em: <https://www.wto.org/english/tratop_e/dispu_e/ dispu_status_e.htm >. Acesso em: 11 jul. 2016. parágrafo 78, p. 25. 
das pelo sistema multilateral do comércio. ${ }^{26}$

No caso do Inovar-Auto, verificam-se potenciais ofensas à regra da nação mais favorecida nos artigos 21 e 22 do Decreto $n^{\circ} 7.819 / 12$, que estabelecem as condições para a redução da alíquota do IPI na importação de veículo.

$\mathrm{O}$ art. 21 do Decreto Regulamentar garante a redução da alíquota do IPI apenas para veículos originários de países do MERCOSUL e do México, nos seguintes termos:

Art. 21. A partir de $1^{\circ}$ de janeiro de 2013 , os veículos classificados nos códigos da TIPI relacionados no Anexo I, quando originários de países signatários dos acordos promulgados pelo Decreto Legislativo $\mathrm{n}^{\circ} 350$, de 21 de novembro de 1991, pelo Decreto $\mathrm{n}^{\circ} 4.458$, de 5 de novembro de 2002, e pelo Decreto $\mathrm{n}^{\circ}$ 6. 500 , de 2 de julho de 2008 , importados por empresa habilitada ao INOVAR-AUTO, nos termos do inciso I ou do inciso III do caput do art. $2^{\circ}$, poderão usufruir, até 31 de dezembro de 2017, de redução de alíquotas do IPI, nos termos do Anexo VIII". (Redação dada pelo Decreto no 8 . 015, de 2013).

Já o art. 22 concede a mesma redução do IPI na importação, desde que os veículos sejam importados do Uruguai e não superem a cota estabelecida no inciso II do artigo; ou que sejam fabricados por empresas não definidas como de grande porte. Eis o dispositivo:

Art. 22. Aplica-se, ainda, a redução de alíquotas do IPI de que trata o art. 21 aos produtos classificados nos códigos da TIPI relacionados no Anexo I, nos termos do Anexo VIII:

I - quando importados ao amparo do acordo promulgado pelo Decreto $\mathrm{n}^{\circ}$ 6. 518 , de 30 de julho de 2008, e pelo Decreto no 7. 658, de 23 de dezembro de 2011;

II - importados diretamente por empresa habilitada ao INOVAR-AUTO, por encomenda ou por sua conta e ordem, até o limite, por ano-calendário:

a) do que resultar da média aritmética da quantidade de veículos importados pela referida empresa nos anos-calendário de 2009 a 2011; ou

b) de quatro mil e oitocentos veículos, caso a operação de que trata a alínea "a" resulte em valor superior;

III - (Revogado pelo Decreto no 8.294 , de 2014);

IV - fabricados por empresas que apresentem volume de produção anual inferior a mil e quinhentas unidades e faturamento anual não

26 Cf. SCHÖN, W. World Trade Organization law and tax law. IBFD Bulletin, Amsterdã, v. 58, n. 7, p. 283-296, 2004. superior a $\mathrm{R} \$ 90.000 .000,00$ (noventa milhões de reais); ou (Redação dada pelo Decreto $n^{\circ}$ 8. 015, de 2013);

$\mathrm{V}$ - quando caracterizados como quadriciclos ou triciclos. (Incluído pelo Decreto nº 8. 015, de 2013).

Ao limitar a redução da alíquota do IPI apenas para veículos importados dos países do MERCOSUL e do México, resta evidenciado que tal vantagem tributária não foi estendida aos demais parceiros comerciais do Brasil, em ofensa à regra da nação mais favorecida prevista no art. I do GATT.

A questão que se coloca é estabelecer se o desvio da cláusula MFN estaria acobertado pelo permissivo contido no art. XXIV do GATT, que introduz exceções àquela regra quando da celebração de acordos comerciais para a formação de uma zona de livre comércio ou união aduaneira ${ }^{27}$.

Em relação à exceção prevista no art. XXIV, vale registrar o entendimento jurisprudencial de que tal permissivo não pode ser utilizado pelos países que pretendem formar a área de livre comércio ou união aduaneira para aumentar barreiras comerciais em relação a terceiros países, criando novas regulamentações comerciais mais onerosas se comparadas àquelas então existentes antes da formação do bloco, inclusive pela introdução de restrições quantitativas que são rechaçadas pelo sistema multilateral. ${ }^{28}$

Nesse sentido, as alíneas "a" e "b" do $\int 5^{\circ}$ do art. XXIV do GATT permitem a formação de uma união aduaneira ou zona de livre comércio desde que:

[...] as tarifas alfandegárias e outras regulamentações
comerciais existentes em cada um dos países
constitutivos e aplicáveis no momento da formação
da zona de livre comércio para países não membros
em tal zona não sejam superiores ou mais restritivas
do que as correspondentes tarifas e outras
regulamentações comerciais existentes nos mesmos
países antes da formação da área de livre comércio. ${ }^{29}$

27 Cf. BOSSCHE, Peter Van den. The law and policy of the World Trade Organization. Text, cases and materials. Cambridge: Cambridge University Press, 2005. p. 650. Cf. MATHIS, James H.; BHAGWATI, Jagdish. Regional trade agreements in the GATT/WTO. Cambridge: Cambridge University Press, 2002. Cf. MAVROIDIS, Petros. Trade in goods. 2. ed. Oxford: Oxford University Press, 2012. p. 124.

28 Cf. WTO. Relatório do Painel em Turkey: Restrictions on Imports of Textiles and Clothing Products, WT/DS34/R. Disponível em: $<$ https://www.wto.org/english/tratop_e/dispu_e/dispu_status_e. htm>. Acesso em: 11 jul. 2016. p. 127-50.

29 Trad. livre do autor. No original: "The duties and other regulations of commerce maintained in each of the constituent territories and applicable at the formation of such free - trade area or 
Assim, para fins deste trabalho, importa observar se, na definição de "outras regulamentações comerciais" prevista na exceção à cláusula MFN para a formação de blocos comerciais, estão incluídas normas tributárias que possam ser consideradas barreira comercial à circulação neutra de bens.

No caso Turkey - Textile, restou decidido que "[...] o sentido ordinário de 'outras regulamentações comerciais' pode ser entendido para incluir qualquer regulamentação que tenha impacto sobre o comércio", ${ }^{30} \mathrm{O}$ que permite concluir que tributos internos se enquadram nessa categoria.

Em suma, a formação de uma zona de livre comércio ou de união aduaneira não concede aos membros da OMC a discricionariedade para a qualquer momento excepcionar a regra MFN, distanciando-se dela após a criação do bloco comercial para criar barreiras comerciais que não existiam quando da formação da área comercial. $^{31}$

Isso porque a jurisprudência da OMC entende que

"[...] os objetivos dos acordos comerciais regionais e do GATT e da OMC sempre foram complementares, e portanto devem ser interpretados consistentemente uns com os outros, com a finalidade de aumentar o comércio e não de erigir barreiras comerciais", 32

the adoption of such interim agreement to the trade of contracting parties not included in such area or not parties to such agreement shall not be higher or more restrictive than the corresponding duties and other regulations of commerce existing in the same constituent territories prior to the formation of the free-trade area". WTO. Relatório do Painel em Turkey: Restrictions on Imports of Textiles and Clothing Products, WT/DS34/R. Disponível em: < https://www. wto.org/english/tratop_e/dispu_e/dispu_status_e.htm>. Acesso em: 11 jul. 2016. parágrafo 9.125, p. 131.

30 Trad. livre do autor. No original: "[...] the ordinary meaning of the terms 'other regulations of commerce' could be understood to include any regulation having an impact on trade". WTO. Relatório do Painel em Turkey: Restrictions on Imports of Textiles and Clothing Products, WT/DS34/R. Disponível em: <https://www.wto.org/ english/tratop_e/dispu_e/dispu_status_e.htm>. Acesso em: 11 jul. 2016. parágrafo 9.120, p. 129.

31 Cf. BOSSCHE, Peter Van den. The law and policy of the World Trade Organization. Text, cases and materials. Cambridge: Cambridge University Press, 2005. p. 656.

32 Trad. livre do autor. No original: "[...] the objectives of regional trade agreements and those of the GATT and the WTO have always been complementary, and therefore should be interpreted consistently with one another, with a view to increasing trade and not to raising barriers to trade". WTO. Relatório do Painel em Turkey: Restrictions on Imports of Textiles and Clothing Products, WT/DS34/R. Disponível em: < https://www.wto.org/english/tratop_e/dispu_e/ dispu_status_e.htm $>$. Acesso em: 11 jul. 2016. parágrafo 9.163, p. 139. principalmente porque deve, sempre, haver a primazia das regras das OMC sobre acordos regionais. ${ }^{33}$

Em outras palavras, um acordo comercial para a formação de uma zona de livre comércio, como os firmados pelo Brasil com os países do Cone Sul e com o México para a formação de uma área de livre comércio relativa à comercialização de automóveis, não pode introduzir, no momento da criação do bloco ou em momento posterior, regulamentações comerciais que sejam mais restritivas comparativamente às então existentes antes da formação da zona de livre comércio.

No caso do Inovar-Auto, a redução do IPI na importação enquadra-se dentro do conceito de "regulamentações comerciais" e, já que tornaram mais onerosas as importações de produtos semelhantes oriundas de outros países, tem impacto negativo no comércio internacional.

Ademais, note-se que o art. 22 da Lei do Inovar-Auto acima transcrito, além de se desviar da regra MFN no inciso I, também introduz restrições quantitativas no inciso II, prática abominada pelo sistema OMC, que no art. XXIV, $₫ 6^{\circ}$ do GATT nem sequer permite a renegociação para introduzir barreiras comerciais desse jaez. ${ }^{34}$

Por fim, o fato de a restrição quantitativa à importação de veículos oriundos do Uruguai ser limitada até 31 . 12. 2017 não a torna compatível com a cláusula MFN ou possível de lhe inserir nas exceções previstas no art. XXIV do GATT. Isso porque, como já decidiu o OSC, “[...] uma medida que não está em conformidade com os tratados da OMC não se torna compatível com o sistema OMC simplesmente por causa da sua limitada duração". ${ }^{35}$

33 WTO. Relatório do Painel em Turkey: Restrictions on Imports of Textiles and Clothing Products, WT/DS34/R. Disponível em: $<$ https://www.wto.org/english/tratop_e/dispu_e/dispu_status_e. htm>. Acesso em: 11 jul. 2016. parágrafo 9.163, p. 139.

34 Cf. WTO. Relatório do Painel em Turkey: Restrictions on Imports of Textiles and Clothing Products, WT/DS34/R. Disponível em: $<$ https://www.wto.org/english/tratop_e/dispu_e/dispu_status_e. htm>. Acesso em: 11 jul. 2016. parágrafo 9.127, p. 131.

35 Trad. livre do autor: "[...] a measure which is not in conformity with the WTO Agreement cannot become WTO compatible just because of its limited duration". WTO. Relatório do Painel em Turkey: Restrictions on Imports of Textiles and Clothing Products, WT/DS34/R. Disponível em: <https://www.wto.org/english/ tratop_e/dispu_e/dispu_status_e.htm>. Acesso em: 11 jul. 2016. parágrafo 9.171, p. 142. 


\section{Princí́pio do Tratamento Nacional: INOVAR-AUTO E O ART. III, § 20, PRIMEIRA SENTENÇA, DO GATT}

O princípio do tratamento nacional é um dos pilares do sistema multilateral do comércio e tem por finalidade garantir a neutralidade concorrencial interna entre produtos/produtores locais e similares estrangeiros, ao proibir que um produto importado seja mais onerado do que o seu similar produzido localmente. ${ }^{36}$

Em inúmeros julgados, a OMC já asseverou que a finalidade básica e geral do tratamento nacional é evitar o protecionismo pela aplicação da tributação doméstica, assegurando igualdade de competição concorrencial entre produtos importados em relação aos produtos domésticos. ${ }^{37}$

Pela ótica tributária, o princípio do tratamento nacional impede que um Estado dispense tratamento tributário privilegiado para produtos locais em detrimento dos similares importados ou aumente a carga tributária de empresas estrangeiras ou do capital estrangeiro em relação ao equivalente nacional. ${ }^{38}$

O princípio do tratamento nacional disciplinado ao longo do art. III do GATT é um dos poucos dispositivos do tratado que restringe expressamente a competência tributária dos países-membros da OMC ao vedar que impostos ou outros tributos internos possam ser utilizados para beneficiar a produção doméstica em desfavor da estrangeira.

O parágrafo $2^{\circ}$ do art. III do GAT'T contém duas sentenças com obrigações distintas e que sempre são

36 Cf. THIEL, Servas van; STEINBACH, Armin. The Effect of WTO Law in the legal order of the European Community: a Judicial protection deficit or a real-political solution, or both? In: LANG, Michael; HERDIN, Juditih; HOFBAUER, Ines (Org.). WTO and direct taxation. Haia: Kluwer Law International, 2005. p. 18.

37 Cf. WTO. Relatório do Painel em Japan: Taxes on Alcoholic Beverages, WT/DS8/RT, WT/DS10/R, WT/DS11/R. Disponível em: $<$ https://www.wto.org/english/tratop_e/dispu_e/dispu_status_e. $\mathrm{htm}>$. Acesso em: 11 jul. 2016. p. 109-10. Cf. WTO. Relatório do Painel em United States: Section 337 of the Tariff Act of 1930, BISD 36S/345. Disponível em: < https://www.wto.org/english/tratop_e/ dispu_e/dispu_status_e.htm>. Acesso em: 11 jul. 2016. p. 38. Cf. WTO. Relatório do Órgão de Apelação em European Communities: Measures Affecting Asbestos and Asbestos-Containing Products, WT/ DS135/AB/R. Disponível em: <https://www.wto.org/english/ tratop_e/dispu_e/dispu_status_e.htm>. Acesso em: 11 jul. 2016. p. 37.

38 Cf. RUPEREZ, J. S. B. Non-fiscal discrimination in the WTO and EC Law: relations and solutions. The EC Tax Journal, v. 4, n. 2, p. $105-110,2000$. analisadas pelo Órgão de Solução de Controvérsias como dispositivos estanques, ${ }^{39}$ metodologia que também será observada neste trabalho. ${ }^{40}$

A primeira sentença do $\int 2^{\circ}$ do art. III estabelece que "[...] os produtos do território de qualquer Parte Contratante, importados por outra Parte Contratante, não estão sujeitos, direta ou indiretamente, a impostos ou outros tributos internos de qualquer espécie superiores aos que incidem, direta ou indiretamente, sobre produtos nacionais". ${ }^{41}$

A partir do caso Canada - Periodicals, de 1997, o Órgão de Solução de Controvérsias estabeleceu um teste de consistência entre medidas domésticas supostamente discriminatórias e a regra do tratamento nacional prevista na primeira sentença do $₫ 2^{\circ}$ do art. III do GATT'. ${ }^{42}$

Tal teste é composto por duas fases sucessivas: primeiro se estabelece se os produtos importados e domésticos são similares (like products). Em seguida se verifica se os produtos importados estão sujeitos a tributação local em excesso àquela aplicada aos produtos domésticos. Havendo resposta positiva para ambas as fases, o OSC entende que há ofensa à primeira sentença do $\ 2^{\circ}$ do art. III do GATT. ${ }^{43}$

Assim, para fins tributários, inicialmente importa estabelecer a similitude entre o produto nacional e o importado (like product analysis), para, então, verificar se o produto importado está sofrendo tributação em excesso comparativamente ao produto similar nacional (excess taxation analysis).

A finalidade da análise de similitude (like product

39 Cf. SHADIKHODJAEV, Sherzod. National Treatment on internal taxation: revisiting GATT Article III:2. Seoul: Korean Institute for International Economic Policy, 2008. p. 12

40 Cf. WTO. Relatório do Órgão de Apelação em Pbilippines: Taxes on Distilled Spirits, WT/DS396/AB/R, WT/DS403/AB/R. Disponível em: <https://www.wto.org/english/tratop_e/dispu_e/ dispu_status_e.htm>. Acesso em: 11 jul. 2016. parágrafo 190, p. 69. 41 Na versão oficial em inglês: "[...] the products of the territory of any contracting party imported into the territory of any other contracting party shall not be subject, directly or indirectly, to internal taxes or other internal charges of any kind in excess of those applied, directly or indirectly, to like domestic products".

42 WTO. Relatório do Órgão de Apelação em Philippines: Taxes on Distilled Spirits, WT/DS396/AB/R, WT/DS403/AB/R. Disponível em: <https://www.wto.org/english/tratop_e/dispu_e/dispu_ status_e.htm>. Acesso em: 11 jul. 2016. parágrafo 7.414, p. 231. 43 Cf. WTO. Relatório do Painel em Canada: Certain Measures Concerning Periodical, WT/DS31/R. Disponível em: < https://www. wto.org/english/tratop_e/dispu_e/dispu_status_e.htm>. Acesso em: 11 jul. 2016. 
analysis) é determinar se a relação de neutralidade de competição entre a produção nacional e a estrangeira está sendo observada pela norma tributária do país importador, já tendo o Órgão de Apelação da OMC decidido que a determinação da similitude entre o produto nacional e importado é, fundamentalmente, uma determinação acerca da natureza e extensão da relação de competitividade entre aqueles produtos em determinado território. ${ }^{44}$

A jurisprudência da OMC consolidou-se no sentido de que, via de regra, a análise de similitude dos produtos (like product analysis) deve ser construída para cada caso concreto com base em uma interpretação restritiva que deve levar em consideração quatro critérios específicos: i) finalidade e uso do produto em determinado mercado; ii) gostos e hábitos dos consumidores; iii) propriedades, natureza e qualidade do produto; e iv) classificação tarifária do produto. ${ }^{45}$

Analisados os quatro critérios acima, para cada caso concreto, "[...] o Painel deve examinar as evidências relacionadas a cada um desses quatro critérios e, então, sopesar todas essas evidências, junto com qualquer outra evidência, ao fazer uma determinação geral se os produtos em questão podem ser caracterizados como similares". ${ }^{46}$

Entretanto, a análise de similitude dos produtos (like product analysis) se simplifica quando o critério discriminatório, adotado pelas medidas tributárias domésticas, passa a ser a origem dos produtos importados e não as características físicas.

44 Cf. Cf. WTO. Relatório do Órgão de Apelação em European Communities: Measures Affecting Asbestos and Asbestos-Containing Products, WT/DS135/AB/R. Disponível em: <https://www.wto.org/ english/tratop_e/dispu_e/dispu_status_e.htm>. Acesso em: 11 jul. 2016. parágrafo 99, p. 37.

45 Cf. WTO. Relatório do Painel em Canada: Certain Measures Concerning Periodical, WT/DS31/R. Disponível em: <https://www. wto.org/english/tratop_e/dispu_e/dispu_status_e.htm>. Acesso em: 11 jul. 2016. parágrafo 5.22, p. 72.; Cf. Relatório do Painel, Thailand: Customs and Fiscal Measures on Cigarettes from the Philippines, WT/DS371/R, parágrafo 7.433, p. 236.

46 Trad. livre do autor. No original: "the Panel should have examined the evidence relating to each of those four criteria and, then, weighed all of that evidence, along with any other relevant evidence, in making an overall determination of whether the products at issue could be characterized as "like" (original com destaque). WTO. Relatório do Órgão de Apelação em European Communities: Measures Affecting Asbestos and Asbestos-Containing Products, WT/DS135/ AB/R. Disponível em: <https://www.wto.org/english/tratop_e/ dispu_e/dispu_status_e.htm>. Acesso em: 11 jul. 2016. parágrafo 109, p. 41.
Isso porque, como restou decidido no Painel US FSC e foi reiterado pelo Órgão de Apelação no caso China - Auto Parts, o mero fato de um produto ter origem estrangeira não o torna diferente (unlike) do produto nacional. ${ }^{47}$

Assim, quando a discriminação tributária ocorre pelo fato de o produto ser de origem importada, a jurisprudência da OMC é firme em dispensar a análise das características físicas entre o produto nacional e o importado com base naqueles quatro critérios comparativos, presumindo que os produtos são similares para fins da primeira sentença do $\ 2^{\circ}$ do art. III do GATTT. ${ }^{48}$

No caso Indonesia - Autos, restou decidida a existência de similitude presumida entre os produtos em razão do critério discriminatório ser a nacionalidade dos produtores ou a origem dos produtos, o que foi suficiente para caracterizar ofensa ao dispositivo nos seguintes termos:

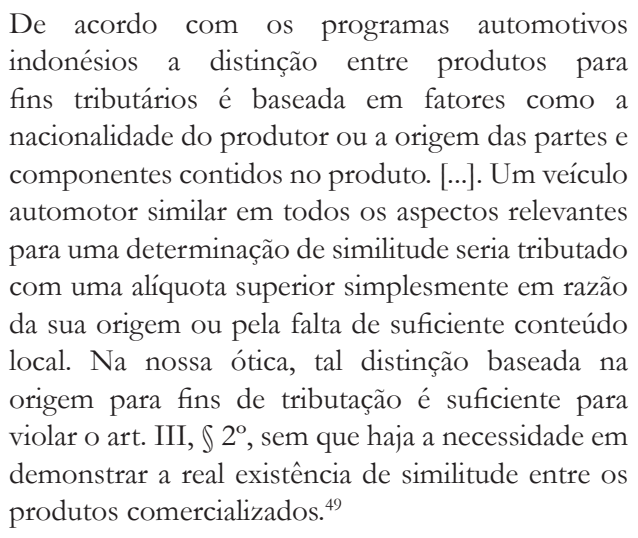

47 Cf. WTO. Relatório do Órgão de Apelação em China: Measures Affecting Imports of Automobile Parts, WT/DS339/AB/R, WT/ DS340/AB/R, WT/DS342/AB/R e Relatório do Painel em China: Measures Affecting Imports of Automobile Parts, WT/DS339/R, WT/DS340/R, WT/DS342/R. Disponível em: <https://www.wto. org/english/tratop_e/dispu_e/dispu_status_e.htm>. Acesso em: 11 jul. 2016. parágrafo 7.216, p. 207. Cf. WTO. Relatório do Órgão de Apelação em Argentina: Measures Affecting the Export of Bovine Hides and the Import of Finished Leather, WT/DS155/R. Disponível em: <https://www.wto.org/english/tratop_e/dispu_e/ dispu_status_e.htm>. Acesso em: 11 jul. 2016. parágrafos 11. 168 e 11. 169, p. 144.

48 Cf. Cf. WTO. Relatório do Painel em Colombia: Indicative Prices and Restrictions on Ports of Entry, WT/DS366/R. Disponível em: $<$ https://www.wto.org/english/tratop_e/dispu_e/dispu_status_e. htm>. Acesso em: 11 jul. 2016. parágrafo 7.182, p. 116.

49 Trad. livre do autor. No original: "Under the Indonesian car programmes the distinction between the products for tax purposes is based on such factors as the nationality of the producer or the origin of the parts and components contained in the product. [...]. An imported motor vehicle alike in all aspects relevant to a likeness determination would be taxed at higher rate simply because of its origin or lack of sufficient local content... In our view, such an 
Posteriormente, no caso Argentina - Hides and Leathers, o Painel decidiu que, quando "a estrutura e o desenho" da medida tributária em questão demonstrar que a discriminação tributária ocorre não em razão das características físicas ou finalidade do produto, mas sim em razão da origem ou qualidade dos importadores ou compradores, a presunção de similitude aplica-se, dispensado o ônus da prova para o Estado que se sente prejudicado. ${ }^{50}$

Consequentemente, na situação em que o ordenamento tributário doméstico discrimina o produto importado com base na origem estrangeira, o Estado, que se sente prejudicado, fica desincumbido do ônus da prova na análise de similitude dos produtos, ou seja, não precisa na reclamação comparar produtos específicos nem demonstrar a aplicação daqueles quatro critérios comparativos para o caso concreto. ${ }^{51}$

Por outro lado, na análise do excesso de tributação incidente em desfavor do produto importado (excess taxation analysis), ${ }^{52}$ que consiste na segunda fase do teste de consistência da tributação doméstica vis-à-vis à regra do tratamento nacional do GATT, a jurisprudência da OMC estabeleceu alguns parâmetros que precisam ser observados pelos países-membros da Organização quando do exercício da competência tributária.

No caso Japan - Alcoholic Beverages II, o Órgão de Apelação decidiu que "mesmo o menor excesso é demasiado" ${ }^{53}$ para fins da discriminação tributária entre o produto importado e o nacional, nos termos da pri-

origin-based distinction in respect of internal taxes suffices in itself to violate Article III: 2, without the need to demonstrate the existence of actually traded like products". WTO. Relatório do Painel em Indonesia: Certain Measures Affecting the Automotive Industry, WT/ DS54/R, WT/DS55/R, WT/DS59/R, WT/DS64/R. Disponível em: <https://www.wto.org/english/tratop_e/dispu_e/dispu_ status_e.htm>. Acesso em: 11 jul. 2016. parágrafo 14.113, p. 351.

50 Cf. WTO. Relatório do Painel em Colombia: Indicative Prices and Restrictions on Ports of Entry, WT/DS366/R. Disponível em: $<$ https://www.wto.org/english/tratop_e/dispu_e/dispu_status_e. htm>. Acesso em: 11 jul. 2016. parágrafo 7.183, p. 117.

51 Cf. WTO. Relatório do Órgão de Apelação em Argentina: Measures Affecting the Export of Bovine Hides and the Import of Finished Leather, WT/DS155/R. Disponível em: <https://www.wto.org/ english/tratop_e/dispu_e/dispu_status_e.htm>. Acesso em: 11 jul. 2016. parágrafo 11. 68, p. 144.

52 Cf. BOSSCHE, Peter Van den. The law and policy of the World Trade Organization. Text, cases and materials. Cambridge: Cambridge University Press, 2005. p. 364.

53 Trad. livre do autor. No original: "Even the smallest amount of 'excess' is too much". WTO. Relatório do Painel em Japan: Taxes on Alcoholic Beverages, WT/DS8/RT, WT/DS10/R, WT/DS11/R. Disponível em: <https://www.wto.org/english/tratop_e/dispu_e/ dispu_status_e.htm>. Acesso em: 11 jul. 2016.p. 23. meira sentença $\operatorname{do} \ 2^{\circ}$, art. III, do GATT.

Assim, qualquer diferença de tratamento tributário beneficiando o produto nacional em detrimento do similar importado, mesmo que seja ínfima, ofende a regra do tratamento nacional.

O entendimento acima baseou-se em prévia decisão proferida no caso US - Malt Beverages, no qual o Painel rejeitou a alegação feita pelos Estados Unidos de que sua tributação doméstica sobre cerveja só discriminava $1,5 \%$ de todas as cervejas importadas e que quantia tão ínfima não seria suficiente para prejudicar a neutralidade concorrencial preconizada pelo tratamento nacional. ${ }^{54}$

$\mathrm{Na}$ realidade, a jurisprudência mais recente da OMC é categórica no sentido de que não apenas uma diferenciação tributária mínima (de minimis) é suficiente para ofender a regra do tratamento nacional, mas que, também, o "mero risco" de discriminação tributária entre produtos nacionais e importados, independentemente de causar distorções no mercado, é suficiente para ofender a primeira sentença do $₫ 2^{\circ}$ do art. III do GATT. ${ }^{55}$

Vê-se, assim, o quão intolerante é a jurisprudência da OMC em relação a medidas tributárias domésticas discriminatórias que privilegiam a produção doméstica em desfavor da similar importada: não apenas uma tributação infimamente superior para o produto importado, mas também o mero risco de discriminação tributária em favor do produto local é suficiente para ofender a regra do tratamento nacional.

Com base em tais parâmetros rígidos em relação à competência tributária doméstica, o Órgão de Solução de Controvérsias já teve oportunidade de analisar os elementos essenciais da norma tributária de alguns dos membros que discriminavam a produção importada em favor da local.

No caso Argentina - Hides and Leathers, restou decidido que o importante para a análise do excesso de tributação é a carga tributária real e não a nominal incidente entre os produtos que concorrem em determinado mercado, isso porque:

54 Cf. WTO. Relatório do Painel em United States: Measures Affecting Alcoholic and Malt Beverages, DS23/R - 39S/206. Disponível em: $<$ https://www.wto.org/english/tratop_e/dispu_e/dispu_status_e. htm>. Acesso em: 11 jul. 2016. parágrafo 5.6, p. 57.

55 Cf. WTO. Relatório do Painel em Mexico: Tax Measures on Soft Drinks and Other Beverages, WT/DS308/R. Disponível em: $<$ https://www.wto.org/english/tratop_e/dispu_e/dispu_status_e. htm>. Acesso em: 11 jul. 2016. parágrafo 8.52. p. 123. 
[...] mesmo quando produtos importados e domésticos estão sujeitos a idênticas alíquotas, a carga tributária real pode ser maior sobre os produtos importados. Este pode ser o caso, por exemplo, quando diferentes métodos de apuração da base de cálculo resultam numa carga tributária real superior para o produto importado. ${ }^{56}$

Consequentemente, a identidade de alíquotas na norma tributária doméstica é irrelevante quando outro elemento essencial do tributo, particularmente a base de cálculo, confere tratamento tributário diferenciado para a produção doméstica, mesmo que de forma ínfima ou até meramente potencial.

A ofensa ao tratamento nacional pela manipulação da base de cálculo dos tributos, por ser uma forma menos evidente de protecionismo se comparada com a mera distinção nominal de alíquotas, tem sido, frequentemente, analisada pela OMC.

No caso US - Malt Beverages, foi reconhecida a ofensa ao art. III, $\ 2^{\circ}$, primeira sentença do GATT, em razão da concessão pelos Estados Unidos de crédito tributário para a redução da base de cálculo de sua tributação federal sobre vendas (federal excise tax). ${ }^{57}$

Tal crédito consistia na dedução, na base de cálculo daquele tributo, do valor de até US\$ 0,90 por galão, dependendo do volume de produção de cada contribuinte, sendo que dele só faziam jus empresas nacionais que produzissem no máximo até 25.000 galões de vinho por ano. $^{58}$

Ainda na decisão US - Malt Beverages, foi declarada ofensa ao art. III, $\int 2^{\circ}$, primeira sentença, do GATT pelas normas tributárias dos Estados americanos do Alabama, Geórgia, Iowa, Nebraska e Novo México, que

56 Trad. livre do autor. No original: “[...] even where imported and domestic products are subject to identical tax rates, the actual tax burden can still be heavier on imported products. This could be the case, for instance, where different methods of computing tax bases lead to a greater actual tax burden for imported products". WTO. Relatório do Órgão de Apelação em Argentina: Measures Affecting the Export of Bovine Hides and the Import of Finished Leather, WT/DS155/R. Disponível em: <https://www.wto.org/english/ tratop_e/dispu_e/dispu_status_e.htm>. Acesso em: 11 jul. 2016. parágrafo 11.183 , p. 147.

57 Cf. WTO. Relatório do Painel em United States: Measures Affecting Alcoholic and Malt Beverages, DS23/R - 39S/206. Disponível em: $<$ https://www.wto.org/english/tratop_e/dispu_e/dispu_status_e. htm>. Acesso em: 11 jul. 2016. parágrafo 5.13 e 5.14, p. 59.

58 WTO. Relatório do Painel em United States: Measures Affecting Alcoholic and Malt Beverages, DS23/R - 39S/206. Disponível em: $<$ https://www.wto.org/english/tratop_e/dispu_e/dispu_status_e. htm>. Acesso em: 11 jul. 2016. parágrafo 2.8, p. 2. conferiam menor alíquota ou isenção do imposto sobre consumo estadual (state excise tax) para vinhos fabricados localmente, mas não concediam iguais benefícios aos vinhos importados. ${ }^{59}$

Ressalte-se, também, que, na eventualidade de haver no ordenamento doméstico tributos que privilegiem algum produto importado, tal privilégio não é suficiente para "compensar" o tratamento discriminatório sofrido por outros produtos importados em desfavor dos similares nacionais. ${ }^{60}$

Por outro lado, a forma de recolhimento de um tributo, também, pode ofender o tratamento nacional se, mesmo com carga tributária idêntica, a forma de recolhimento do tributo incidente sobre o produto estrangeiro for mais onerosa do que a aplicada para o similar doméstico, ${ }^{61}$ não sendo válido o argumento de que a discriminação ocorre para fins de eficiência da administração tributária. ${ }^{62}$

Isso porque o excesso discriminatório não envolve, apenas, tributos internos (internal taxes), mas também qualquer outra cobrança, de qualquer tipo (other internal charges of any kind), no que se incluem medidas administrativas tributárias adotadas para maximizar a arrecadação e a fiscalização de tributos.

Note-se, também, que o excesso de tributação entre produtos similares, nacionais e importados pode ocorrer direta ou indiretamente. No caso México - Taxes on Soft Drinks, havia excesso de tributação no produto final importado (refrigerantes) quando estes utilizavam determinado insumo (adoçante de beterraba ou de milho), o que aumentava, exponencialmente, a tributação sobre tais insumos.

59 Cf. WTO. Relatório do Painel em United States: Measures Affecting Alcoholic and Malt Beverages, DS23/R - 39S/206. Disponível em: $<$ https://www.wto.org/english/tratop_e/dispu_e/dispu_status_e. $\mathrm{htm}>$. Acesso em: 11 jul. 2016. parágrafo 5.20, p. 61.

60 Cf. WTO. Relatório do Órgão de Apelação em Argentina: Measures Affecting the Export of Bovine Hides and the Import of Finished Leather, WT/DS155/R. Disponível em: <https://www.wto.org/ english/tratop_e/dispu_e/dispu_status_e.htm>. Acesso em: 11 jul. 2016. parágrafo 11.196 , p. 149.

61 Cf. WTO. Relatório do Painel em Thailand: Customs and Fiscal Measures on Cigarettes from the Philippines, WT/DS371/R. Disponível em: < https://www.wto.org/english/tratop_e/dispu_e/dispu_status_e.htm>. Acesso em: 11 jul. 2016. parágrafo 7.611, p. 277. 62 Cf. Relatório do Órgão de Apelação em Argentina: Measures Affecting the Export of Bovine Hides and the Import of Finished Leather, WT/DS155/R. Disponível em: <https://www.wto.org/ english/tratop_e/dispu_e/dispu_status_e.htm >. Acesso em: 11 jul. 2016. parágrafo 11.144, p. 139. 
Consequentemente, o Órgão de Apelação decidiu que, no caso mexicano, “[...] tributos diretamente incidentes sobre produtos finais podem indiretamente afetar as condições de competição entre o insumo importado e o doméstico e, assim, subsumir-se à primeira sentença do $\int 2^{\circ}$ do art. III". ${ }^{63}$

Já no caso Argentina - Hides and Leathers, a Argentina sustentava que a diferença de tratamento tributário em excesso, consubstanciada na exigência de pagamento na importação do imposto de renda por pessoa física, o que não ocorria na compra de produto similar doméstico, seria justificada em razão da diferença da capacidade contributiva entre o importador e o concorrente nacional.

$\mathrm{O}$ argumento argentino foi, expressamente, rechaçado pelo Painel, nos seguintes termos:

Em relação ao argumento argentino de que a discriminação é justificada em razão da capacidade contributiva dos contribuintes em questão, nós apenas reiteramos que já expressamos anteriormente o entendimento de que não é permitido, sob a primeira sentença do $\int 2^{\circ}$ do art. III, impor diferentes cargas tributárias sobre produtos similares importados e nacionais com base nas características ou circunstâncias do comprador ou do vendedor daqueles produtos. ${ }^{64}$

Por fim, registre-se que, para fins da primeira sentença do parágrafo $2^{\circ}$ do art. III do GATT', não é necessário demonstrar que a tributação em excesso do produto similar importado se dá para fins de proteção da produção doméstica. Tal requisito é necessário, apenas, para situações que se enquadram na segunda sentença

63 Trad. livre do autor. No original: "[...] taxes directly imposed on finished products can indirectly affect the conditions of competition between imported and like domestic input and therefore come within the scope of Article III: 2, first sentence". WTO. Relatório do Painel em Mexico: Tax Measures on Soft Drinks and Other Beverages, WT/DS308/R. Disponível em: <https://www.wto.org/english/ tratop_e/dispu_e/dispu_status_e.htm>. Acesso em: 11 jul. 2016. parágrafo 8.44, p. 122.

64 Trad. livre do autor. No original: "With respect to Argentina's argument that that differential is justified in light of the tax-bearing ability of the taxable persons concerned, we simply recall that we have previously expressed the view that it is not permissible under Article III:2, first sentence, to impose different tax burdens on imported and like domestic products on the basis of the circumstances or characteristics of the purchasers or sellers of those products". Relatório do Órgão de Apelação em Argentina: Measures Affecting the Export of Bovine Hides and the Import of Finished Leather, WT/DS155/R. Disponível em: <https://www.wto.org/english/ tratop_e/dispu_e/dispu_status_e.htm>. Acesso em: 11 jul. 2016. parágrafo 11.264, nota de Rodapé no 539, p. 162. do mesmo parágrafo ${ }^{65}$.

Ao subsumir o entendimento jurisprudencial acima com o Inovar-Auto, vê-se que o critério escolhido pelos programas brasileiros para diferenciar a tributação do IPI sobre automóveis e autopeças é, justamente, a origem estrangeira/nacional dos produtos, já que a concessão do crédito presumido e da redução da alíquota do IPI na importação está atrelada à origem dos produtos em questão, o que presume a similitude entre os produtos nacionais, objeto do Inovar-Auto e os produtos importados.

Em relação à análise sobre o excesso de tributação, que é a segunda fase do teste de consistência erigido para aferir a compatibilidade entre as medidas tributárias domésticas e a primeira sentença do $\ 2^{\circ}$ do art. III do GAT'T, viu-se que a jurisprudência da OMC sedimentou o entendimento de que qualquer diferença de tributação, mesmo que ínfima ou meramente potencial em desfavor do produto importado, é suficiente para ofender o tratamento nacional. ${ }^{66}$

Aplicando-se tal entendimento aos benefícios concedidos pelo Inovar-Auto, é possível constatar que há uma tributação mais onerosa para os veículos que não sejam produzidos no Brasil.

Nesse sentido, vale ressaltar que o crédito presumido do IPI apurado na fabricação local de veículos, na forma como estabelecido no Inovar-Auto, representa, na prática, sobretaxa de 30\% na importação de veículos oriundos do exterior.

Isso porque, de acordo com o $\$ 1^{\circ}$ do art. 14 do Decreto $\mathrm{n}^{\circ}$ 7. 819/12, o crédito presumido do IPI, apurado pelos dispêndios sobre insumos estratégicos e ferramentaria, a ser utilizado para pagamento do IPI devido, na saída interna dos produtos discriminados no Decreto, fica limitado ao valor correspondente ao que resultaria da aplicação de 30\% sobre a base de cálculo prevista na legislação do IPI.

Tal limitação implica, na prática, reajuste geral da alíquota do IPI para todos os veículos (nacionais e importados), mas, apenas, os produtos nacionais podem ter alíquota reduzida em até $30 \%$ por ser produzidos

65 Relatório do Órgão de Apelação em Argentina: Measures Affecting the Export of Bovine Hides and the Import of Finished Leather, WT/DS155/R. Disponível em: <https://www.wto.org/english/ tratop_e/dispu_e/dispu_status_e.htm>. Acesso em: 11 jul. 2016. parágrafo 11.137, p. 137.

66 Cf. item 4. 
localmente, já que esta é a condição para a obtenção do crédito presumido e pelo fato de o crédito presumido dever ser utilizado nas operações do mercado interno.

Note-se, ainda, que, na hipótese de restar saldo do crédito presumido apurado sobre dispêndios com insumos estratégicos e ferramentaria e utilizado para o pagamento do IPI devido na saída dos produtos discriminados no Decreto, o valor remanescente poderá ser utilizado para abater o IPI devido na importação de veículos, de acordo com o $₫ 2^{\circ}$ do art. 14 do Decreto $n^{\circ}$ 7. 819/12. Contudo, mais uma vez está limitado o uso do saldo ao valor correspondente ao que resultaria da aplicação de 30\% sobre a base de cálculo prevista na legislação do IPI (art. 14, \ $2^{\circ}, \mathrm{I}$ ), além de só poder ser utilizado na importação de no máximo 4.800 veículos por ano-calendário (art. 14, $\ 2^{\circ}, \mathrm{II}$ ), o que reitera o excesso de tributação sobre o veículo importado.

A seu turno, o crédito presumido apurado sobre os dispêndios incorridos em pesquisa, desenvolvimento tecnológico, inovação tecnológica, recolhimento ao FNDCT, capacitação de fornecedores e engenharia e tecnologia industrial básica deve primeiramente ser utilizado para dedução do valor do IPI devido pelas operações no mercado interno do contribuinte (art. 15, \ $\left.1^{\circ}, \mathrm{I}\right)$. Havendo saldo, o mesmo pode ser transferido para as filiais do contribuinte ou ser objeto de pedido de ressarcimento ou compensação (art. 15, $\mathbb{1} 1^{\circ}$, II e III).

O caráter mandatório da forma com o crédito presumido deve ser fruído, i. e. primeiro nas operações do mercado interno e posteriormente via transferência, restituição ou compensação, sem a indicação da possibilidade de uso na importação, também demonstra que os veículos importados restam mais onerados pelo IPI.

Some-se a isso o fato de que o crédito presumido do IPI apurado na importação tem uso restrito a $1 / 48 \mathrm{da}$ capacidade de produção anual prevista no projeto de investimento (art. 16, I) e só pode ser utilizado para abater o IPI na importação de veículos constantes no referido projeto de investimento (art. 13, $\int 1^{\circ}$, III). Em outras palavras, há limitação quantitativa e qualitativa para os veículos importados se beneficiar do crédito presumido do IPI, o que, também, os coloca em desvantagem concorrencial com o similar nacional.

Em suma, analisando-se os dispositivos do Inovar-Auto na ótica do teste de consistência construído pela jurisprudência da OMC, é de concluir pela similitude dos produtos importados e nacionais objetos do programa e pelo excesso de tributação de IPI que sofre os produtos importados relativamente aos nacionais, o que resulta em ofensa à primeira sentença do $₫ 2^{\circ}$ do art. III do GATTT.

\section{Princí́pio do Tratamento Nacional: $O$ INOVAR-Auto E O ART. III, § $4^{\circ}$ DO GATT}

De início, assevere-se que uma medida tributária doméstica pode ser contestada simultaneamente por ofensa ao princípio do tratamento nacional com base no $\$ 2^{\circ}$ e no $\int 4^{\circ}$ do art. III do GATT. O Órgão de Apelação da OMC rejeitou argumento de que a jurisprudência do órgão se teria pacificado no sentido de que medidas fiscais são sempre contestadas em face do $\int 2^{\circ}$ e medidas não tributárias, por outro lado, seriam confrontadas pelo $\$ $4^{\circ}$ do art. 3 do GATT. ${ }^{67}$

$\mathrm{O} \ 4^{\circ}$ do art. III do GATT estabelece que:

4. Os produtos de território de uma Parte Contratante que entrem no território de outra Parte Contratante não usufruirão tratamento menos favorável que o concedido a produtos similares de origem nacional, no que diz respeito às leis, regulamento e exigências relacionadas com a venda, oferta para venda, compra, transporte, distribuição e utilização no mercado interno. Os dispositivos deste parágrafo não impedirão a aplicação de tarifas de transporte internas diferenciais, desde que se baseiem exclusivamente na operação econômica dos meios de transporte e não na nacionalidade do produto. ${ }^{68}$

No julgado Korean - Various Measures on Beef, foram fixados os seguintes requisitos para a análise da violação do parágrafo acima transcrito: a) o produto importado e o nacional devem ser similares (like products); b) a medida doméstica contestada deve ser enquadrada como "leis, regulamentos, ou requerimento que afetem a venda interna, oferta à venda, compra, transporte, distribuição ou uso"; e c) o produto importado não deve receber tratamento menos favorável do que o dispensado ao produto doméstico. ${ }^{69}$

67 WTO. Relatório do Painel em Mexico: Tax Measures on Soft Drinks and Other Beverages, WT/DS308/R. Disponível em: <https:// www.wto.org/english/tratop_e/dispu_e/dispu_status_e.htm $>$. Acesso em: 11 jul. 2016. parágrafo 8.13, p. 116.

68 Na versão oficial em inglês: " 4 . The products of the territory of any contracting party imported into the territory of any other contracting party shall be accorded treatment no less favourable than that accorded to like products of national origin in respect of all laws, regulations and requirements affecting their internal sale, offering for sale, purchase, transportation, distribution or use".

69 Cf. WTO. Relatório do Órgão de Apelação em Korean: Measures 
Os três requisitos acima foram postos numa perspectiva temporal no caso China - Auto Parts, quando se decidiu que, primeiramente, verifica-se se os produtos domésticos e importados são similares e se a lei, regulamento ou requerimento afetam a venda interna, a oferta à venda, a compra, o transporte ou distribuição dos produtos similares. Sendo positiva essa primeira análise, define-se se tais medidas que afetam a competição interna conferem tratamento "menos favorável" ao produto importado. $^{70}$

A perspectiva temporal elaborada no caso China Auto Parts baseou-se no precedente US - FSC, quando o Órgão de Apelação decidiu não ser quaisquer normas domésticas abrangidas pelo dispositivo, mas apenas aquelas que afetam a competição interna. Restou decidido no precedente que analisava a tributação sobre a renda americana que “[...]a palavra 'afetando' possibilita a definição dos tipos de medidas que precisam adequar-se às obrigações para não conferir um 'tratamento não menos favorável' ao produto similar importado, como previsto no art. III, $\int 4^{\mathrm{o}}{ }^{71}$

Assim, verifica-se que a jurisprudência da OMC estabeleceu mais um teste para aferir a compatibilidade entre normas tributárias domésticas e as regras do sistema multilateral. Por esse novo teste, primeiro é necessário estabelecer a similitude entre os produtos em questão e se a medida doméstica afeta a neutralidade de competição entre eles.

Em relação à determinação da similitude entre o produto nacional e o produto importado, aplicam-se os precedentes analisados no tópico anterior quando da verificação do mesmo requisito no $\ 2^{\circ}$ do art. III, prin-

Affecting Imports of Fresh, Chilled and Frozen Beef, Various Measures on Beff, WT/DS161/AB/R/WT/DS169/AB/R. Disponível em: <https://www.wto.org/english/tratop_e/dispu_e/ dispu_status_e.htm>. Acesso em: 11 jul. 2016. parágrafo 133, p. 39. 70 Cf. WTO. Relatório do Painel em China: Measures Related to the Exportation of Various Raw Materials, WT/DS394/R WT/ DS395/R WT/DS398/R. Disponível em: <https://www.wto.org/ english/tratop_e/dispu_e/dispu_status_e.htm>. Acesso em: 11 jul. 2016. parágrafo 7.230, p. 209-10.

71 Trad. livre do autor. No original: "Thus the word 'affecting' assist in defining the types of measures that must conform to the obligation not to accord 'less favourable treatment' to like imported products, which is set out in Article III:4”. WTO. Relatório do Órgão de Apelação em United States: Tax Treatment for "Foreign Sales Corporations", W T/DS108/AB/RW e Relatório do Painel em United States: Tax Treatment for "Foreign Sales Corporation", WT/DS108/RW. Disponível em: <https://www.wto.org/english/tratop_e/dispu_e/ dispu_status_e.htm>. Acesso em: 11 jul. 2016. parágrafo 208, p. 65. cipalmente a impossibilidade de haver discriminação tributária em razão da origem estrangeira do produto.

$\mathrm{Na}$ realidade, a jurisprudência da OMC é pacífica em asseverar que a definição de like products no $\ 2^{\circ}$ do art. III do GATT é mais restrita do que a do $\$ 4^{\circ} .{ }^{72}$ Consequentemente, produtos que se enquadram naquele dispositivo, automaticamente, se incluem no que ora se analisa.

Em relação à previsão no ordenamento jurídico interno ("leis, regulamentos e exigências"), incluem-se não apenas normas de caráter mandatório, mas também medidas que conferem opção ao particular, mas desde que condicionando determinado benefício à adesão. ${ }^{73}$

Apenas normas do ordenamento jurídico que afetam a competitividade do produto importado em face do doméstico se enquadram no $\int 4^{\circ}$ do art. III do GATTT. O Órgão de Apelação já decidiu que o escopo da palavra affecting, na versão original em inglês, é amplo. No caso China - Auto Parts, foram analisados vários precedentes concluindo-se que:

[...] a palavra "affecting" no $\int 4^{\circ}$ do art. III do GAT'T tem sido interpretada para abranger não apenas leis e regulamentos que diretamente disciplinam as condições de venda ou de compra, mas também qualquer lei ou regulamentos que possam adversamente modificar as condições de competição entre os produtos doméstico e importado. $^{74}$

Medidas tributárias que incentivam produtores domésticos a comprar insumos locais em detrimento do

72 Cf. WTO. Relatório do Órgão de Apelação em European Communities: Measures Affecting Asbestos and Asbestos-Containing Products, WT/DS135/AB/R. Disponível em: <https://www.wto.org/ english/tratop_e/dispu_e/dispu_status_e.htm >. Acesso em: 11 jul. 2016. parágrafo 99 , p. 37.

73 Cf. WTO. Relatório do Órgão de Apelação em Canada: Certain Measures Affecting the Automotive Industry, WT/DS139/AB/R, WT/DS142/AB/R e Relatório do Painel em Canada: Certain Measures Affecting the Automotive Industry, WT/DS139/R, WT/DS142/R. Disponível em: <https://www.wto.org/english/tratop_e/dispu_e/ dispu_status_e.htm>. Acesso em: 11 jul. 2016. parágrafo 10.73, pp. 368-9.

74 Trad. livre do autor. No original: "[...] furthermore, the word 'affecting' in Article III:4 of the GATT has been interpreted to cover not only laws and regulations which directly govern the conditions of sale or purchase but also any laws or regulations which might adversely modify the conditions of competition between domestic and imported products". WTO. Relatório do Órgão de Apelação em China: Measures Affecting Imports of Automobile Parts, WT/ DS339/AB/R, WT/DS340/AB/R, WT/DS342/AB/R e Relatório do Painel em China: Measures Affecting Imports of Automobile Parts, WT/DS339/R, WT/DS340/R, WT/DS342/R. Disponível em: <https://www.wto.org/english/tratop_e/dispu_e/dispu_status_e. htm>. Acesso em: 11 jul. 2016. parágrafo 7.251, p. 214. 
similar importado "afetam" as condições de competição do mercado e, consequentemente, ofendem o $\$$ $4^{\circ}$ do art. III. Foi a decisão do Painel no caso China - Auto Parts, que analisava medidas tributárias chinesas que concediam redução da tributação interna para as fábricas que, na montagem final de veículos, utilizassem determinado quantitativo de peças produzidas localmente. $^{75}$

O caso acima reiterou o leading case US - FSC, que continha medida tributária condicionando o benefício de redução da tributação da renda obtida no exterior à utilização de insumos produzidos/montados nos Estados Unidos, o que foi entendido como medida que "afetava" a competição entre o produto doméstico e o importado, nos seguintes termos:

Nós consideramos que uma medida pela qual o uso
de produtos domésticos - mas não de importados
- contribui na obtenção de uma vantagem tem um
impacto nas condições de competição entre os
produtos doméstico e importado e, assim, 'afeta'
o "uso" interno dos produtos importados, mesmo
que a medida preveja outros meios para a obtenção
da vantagem, como o uso de insumos domésticos.

A mesma metodologia foi aplicada no caso India Autos, quando se declarou a incompatibilidade da legislação indiana que estabelecia que o uso mínimo de peças produzidas localmente para a fabricação de carros na Índia afetava a competição no mercado local. ${ }^{77}$

Por fim, deve-se demonstrar que a medida tributária que afeta o produto importado lhe confere tratamento menos favorável do que o dispensado ao produto similar doméstico.

75 WTO. Relatório do Órgão de Apelação em China: Measures Affecting Imports of Automobile Parts, WT/DS339/AB/R, WT/ DS340/AB/R, WT/DS342/AB/R e Relatório do Painel em China: Measures Affecting Imports of Automobile Parts, WT/DS339/R, WT/DS340/R, WT/DS342/R. Disponível em: <https://www.wto. org/english/tratop_e/dispu_e/dispu_status_e.htm>. Acesso em: 11 jul. 2016. parágrafo 7.256, p. 216.

76 Trad. livre do autor. No original: “[...] we consider that a measure pursuant to which the use of domestic - but not imported products contributes to obtaining an advantage has an impact on the conditions of competition between domestic and imported products and thus 'ffects' the internal 'se' of imported products, even if the measures allows for other means to obtain the advantage, such as the use of domestic inputs other than products". Relatorio do Painel em United States: Tax Treatment for "Foreign Sales Corporations". Recourse to Article 21. 5 of the DSU by the European Communities, WT/DS108/RW, parágrafo 8.148, p. 55.

77 Cf. WTO. Relatório do Painel em India: Measures Affecting the Automotive Sector, WT/DS146/R, WT/DS175/R. Disponível em: $<$ https://www.wto.org/english/tratop_e/dispu_e/dispu_status_e. htm>. Acesso em: 11 jul. 2016. parágrafo 7.305, p. 164.
Tratamento menos favorável para o produto similar importado significa que as medidas tributárias modificam as condições de competição no mercado em favor dos produtos nacionais. ${ }^{78}$ Assim como se dá em relação à primeira sentença do $\int 2^{\circ}$ do art. III, mesmo uma distorção mínima da competição em favor do produto nacional já é suficiente para caracterizar o tratamento menos favorável em relação ao produto similar importado. $^{79}$

Na decisão proferida no caso EC - Seal Products, o Órgão de Apelação resumiu o fundamento de vários precedentes que analisavam no que consiste o tratamento não menos favorável a ser dispensado ao produto similar importado, tendo concluído aquele Órgão Julgador que há quebra da isonomia de tratamento quando a neutralidade concorrencial no mercado interno deixa de existir, alterando-se as oportunidades de competição em favor do produto doméstico. ${ }^{80}$

Os requisitos postos pelos precedentes acima analisados se fazem presentes no caso do programa Invar-Auto. Tal programa deriva da Lei no 12.715/2012, cujos benefícios são esmiuçados por um decreto regulamentar (Decreto n ${ }^{\circ} 7.819 / 12$ ) e várias portarias ministeriais, normas que se enquadram no conceito de "lei, regulamentos e requerimentos" previsto no $₫ 4^{\circ}$ do art. III do GATT.

O fato de os benefícios tributários do Inovar-Auto não serem mandatórios, já que só é possível deles usufruir após a habilitação provocada pelo contribuinte no MICD, não afasta o enquadramento das normas legais do programado conceito de "lei, regulamentos e requerimentos", uma vez que a fruição dos benefícios tributários é condicionada à adesão ao programa.

As normas do Inovar-Auto afetam a competitividade do produto importado ante o similar nacional no mercado interno brasileiro, já que, como visto, a juris-

78 Cf. WTO. Relatório do Órgão de Apelação em Korean: Measures Affecting Imports of Fresh, Chilled and Frozen Beef, Various Measures on Beff, WT/DS161/AB/R/WT/DS169/AB/R. Disponível em: <https://www.wto.org/english/tratop_e/dispu_e/ dispu_status_e.htm>. Acesso em: 11 jul. 2016. parágrafo 137, p. 41. 79 Cf. WTO. Relatório do Painel em Canada: Measures Relating to Exports of Wheat and Treatment of Imported Grain, WT/DS276/R. Disponível em: <https://www.wto.org/english/tratop_e/dispu_e/ dispu_status_e.htm>. Acesso em: 11 jul. 2016. parágrafo 6.190, nota de rodapé 281, p. 177.

80 Cf. Relatório do Órgão de Apelação em European Communities: Measures Prohibiting the Importation and Marketing of Seal Product, WT/DS400/AB/R, WT/DS401/AB/R, parágrafo 5.101, p. 123. 
prudência da OMC entende que o vocábulo affecting, relativo à versão em Língua Inglesa, $\int 4^{\circ}$ do art. III do GATT, cobre não apenas normas que diretamente regulam as condições de compra e venda dos produtos, mas também aquelas que podem prejudicar as condições de competição entre o produto doméstico e o importado.

Nesse sentido, passam-se a analisar as duas modalidades previstas no Inovar-Auto para obtenção do crédito presumido do IPI, isto é, quando da realização do processo produtivo local (art. 12 do Decreto ${ }^{\circ} 7$. 819/21) e da importação de veículos (art. 13 do Decreto $n^{\circ}$ 7. 819/21), para verificar se, em relação à obtenção de tais benefícios, há comprometimento da neutralidade concorrencial em desfavor do produto importado.

Em razão de a primeira espécie do crédito presumido do IPI estar atrelada à realização de dispêndios incorridos no processo produtivo local de veículos, apenas os contribuintes que produzem veículos no Brasil têm a possibilidade de auferir tal benefício. Consequentemente, aquele contribuinte que não produz, mas apenas importa veículos, não incorre em gastos e, assim, não consegue acumular crédito presumido do IPI suficiente para minorar a carga tributária.

Isso porque, como visto no tópico 2, a apuração de crédito presumido no processo produtivo relacionada a dispêndios com insumos estratégicos e ferramentaria só ocorre se os fornecedores dos produtos forem nacionais, o que implica a constatação de que não basta, apenas, montar o veículo no país, sendo necessário, também, que os insumos e o maquinário utilizado na montagem final do veículo sejam produzidos no Brasil. É justamente esse "adensamento" da cadeia produtiva nacional a finalidade do Inovar-Auto.

Consequentemente, o importador, por não realizar processo produtivo local, não consegue acumular saldo expressivo de crédito presumido do IPI, o que significa reconhecer que a carga tributária desse imposto sobre os produtos importados é superior àquele incidente aos similares fabricados nacionalmente, já que, apenas, os produtores locais têm condição de acumular saldo de crédito presumido para abater nas operações internas.

Já o crédito presumido apurado na importação de veículos só pode ser auferido por contribuintes que tenham projeto de investimentos aprovados para instalação ou ampliação da capacidade produtiva local. Esses contribuintes poderão apurar o crédito presumido correspondente ao resultado da aplicação da alíquota de
$30 \%$ sobre a base de cálculo do imposto na saída dos produtos do estabelecimento do importador.

Mais uma vez, verifica-se que os veículos importados se submetem, na prática, à sobretaxa de 30\%, a qual é eliminada, seletivamente, apenas, para aqueles que são importados por produtores locais e desde que tais produtores cumpram uma série de requisitos qualitativos (i. e. cumprimento do cronograma do projeto de investimento de produção local) e quantitativos (i.e. quantidade de veículos importados é limitada a 1/24 da capacidade de produção prevista no projeto de investimento), o que comprova que o crédito presumido na importação, também, afeta a concorrência entre veículos importados e nacionais.

Em suma, constata-se que a lei e os regulamentos que instituem os benefícios tributários do Inovar-Auto afetam a venda interna dos produtos similares importados, que se sujeitam a tributação menos favorável aquela destinada a produtos nacionais, restando assim demonstrada a ofensa ao $\int 4^{\circ}$ do art. III, do GAT'T.

\section{Princípio do Tratamento Nacional: o INOVAR-AUTO E O ART. III, § 5 DO GATT}

Há uma sobreposição entre os $\iint 4^{\circ}$ e $5^{\circ}$ do art. III do GATT, já que o último também exige que a norma doméstica seja enquadrada como regulamentação interna, reclamando o uso de produtos domésticos em ofensa ao princípio do tratamento nacional. O $\int 5^{\circ}$ do art. III do GATT estabelece:

5. Nenhuma Parte Contratante estabelecerá ou
manterá qualquer regulamentação quantitativa
interna que se relacione com a mistura,
transformação ou utilização de produtos em
quantidades ou proporções determinadas e que
exija, direta ou indiretamente o fornecimento
pelas fontes produtoras nacionais, de quantidade
ou proporção determinada de um produto
enquadrado na regulamentação. Além disso,
nenhuma Parte Contratante aplicará de outro
modo, regulamentações quantitativas internas, de
forma a contrariar os princípios estabelecidos no
parágrafo $1^{\circ} .^{81}$

81 Na versão oficial em inglês: "5. No contracting party shall establish or maintain any internal quantitative regulation relating to the mixture, processing or use of products in specified amounts or proportions, which requires, directly or indirectly, that any specified amount or proportion of any product, which is the subject of the regulation, must be supplied from domestic sources. Moreover, no 
A primeira sentença do dispositivo acima transcrito estabelece os seguintes requisitos para que reste configurada a violação: a) que a medida seja uma "regulamentação interna"; b) que tal medida seja quantitativa, relacionada à mistura, transformação ou utilização de produtos em quantidades ou proporções determinadas; e c) que as exigências requeiram, direta ou indiretamente, o uso de produtos domésticos.

No caso China - Auto Parts, a legislação tributária da China exigia que até $60 \%$ de autopeças utilizadas na composição final de veículo montado naquele país fosse nacional, sob pena de aplicar maior alíquota do tributo interno chinês incidente sobre a venda interna de automóveis. $^{82}$

Por tal razão, a Europa alegava que as medidas tributárias chinesas infringiam a primeira sentença do $\int 5^{\circ}$ do art. III do GATT, já que "[...] as medidas estabeleciam limites máximos e proporções de autopeças importadas que não deveriam ser superadas quando da utilização na montagem dos veículos". ${ }^{83}$

Contudo, no caso US - Tobacco, ${ }^{84}$ o Painel atestou que, tanto o $\int 4^{\circ}$ quanto o $\int 5^{\circ}$ do art. III do GATT disciplinam regulamentos internos, mas asseverou que o $\int 5^{\circ}$ é mais específico. ${ }^{85}$ É a já mencionada sobreposição entre ambos os dispositivos, razão pela qual muitas

contracting party shall otherwise apply internal quantitative regulations in a manner contrary to the principles set forth in paragraph 1". 82 Cf. WTO. Relatório do Órgão de Apelação em China: Measures Affecting Imports of Automobile Parts, WT/DS339/AB/R, WT/ DS340/AB/R, WT/DS342/AB/R e Relatório do Painel em China: Measures Affecting Imports of Automobile Parts, WT/DS339/R, WT/DS340/R, WT/DS342/R. Disponível em: < https://www.wto. org/english/tratop_e/dispu_e/dispu_status_e.htm $>$. Acesso em: 11 jul. 2016.

83 Trad. livre do autor. No original: “[...] the measures set out maximum amounts and proportions of imported auto parts which must not be surpassed when using them in the assembly of vehicles". WTO. Relatório do Órgão de Apelação em China: Measures Affecting Imports of Automobile Parts, WT/DS339/AB/R, WT/ DS340/AB/R, WT/DS342/AB/R e Relatório do Painel em China: Measures Affecting Imports of Automobile Parts, WT/DS339/R, WT/DS340/R, WT/DS342/R. Disponível em: < https://www.wto. org/english/tratop_e/dispu_e/dispu_status_e.htm $>$. Acesso em: 11 jul. 2016. parágrafo 4. 26, p. 12.

84 Cf. WTO. Relatório do Painel em United States: Measures Affecting the Importation, Internal Sale and Use of Tobacco, BISD 41S/I/131. Disponível em: <https://www.wto.org/english/ tratop_e/dispu_e/dispu_status_e.htm >. Acesso em: 11 jul. 2016. parágrafo 72 , p. 26.

85 WTO. Relatório do Painel em United States: Measures Affecting the Importation, Internal Sale and Use of Tobacco, BISD 41S/I/131. Disponível em: <https://www.wto.org/english/tratop_e/dispu_e/ dispu_status_e.htm>.Acesso em: 11 jul. 2016. disputas que, inicialmente, se fundamentaram nesses dois parágrafos foram logo encerradas quando do enquadramento da medida tributária no $\int 4^{\circ}$, com base no princípio de "economia judicial". 86

No caso do Inovar-Auto há ofensa ao $\ 5^{\circ}$ do art. III do GATT ao se exigir das empresas que produzem veículos no Brasil que realizem, em pelo menos $80 \%$ dos veículos fabricados, uma quantidade mínima de atividades fabris e de infraestrutura, dependendo do tipo do veículo e do ano de produção, nos termos do art. $7^{\circ}$ do Decreto no $7.819 / 12$.

Tais atividades fabris e de infraestrutura correspondem, de acordo com o Anexo III do Decreto regulamentar, a atividades relacionadas a estampagem, soldagem, tratamento anticorrosivo para pintura, injeção de plástico, entre outras, as, quais, a seu turno, só podem ser realizadas quando o fabricante adquire insumos estratégicos e ferramentaria.

A Portaria MDIC no 257/14 define insumos estratégicos como "[...] toda a matéria-prima, partes, peças e componentes utilizados na fabricação e incorporados fisicamente aos veículos de que trata o Anexo I do Decreto $n^{\circ}$ 7. 819, de 2012" (art. $1^{\circ}$ ). Já por ferramentaria entende "[...] o ferramental, específico por tipo de peça e acoplado a uma máquina, usado para estampar ou injetar autopeças destinadas ao processo de fabricação a que se refere o art. $1^{\circ}$ " $\left(\operatorname{art.} 2^{\circ}\right)$.

Em outras palavras, o quantitativo mínimo de atividades fabris e de infraestrutura de engenharia que o fabricante deve realizar em pelo menos $80 \%$ dos veículos que produz no Brasil, como condição de habilitar-se no Inovar-Auto, exige que o contribuinte adquira insumos estratégicos e ferramentaria.

A seu turno, o $\int 6^{\circ}$ do art. 32-B do decreto estabelece que os dispêndios com insumos estratégicos e ferramentaria só geram crédito presumido do IPI se adquiridos de fornecedores que tenham previamente firmado Termo de Compromisso com o MDIC.

Visto que somente fornecedores instalados no Brasil têm condição de firmar o referido Termo de Compro-

86 Cf. WTO. Relatório do Órgão de Apelação em China: Measures Affecting Imports of Automobile Parts, WT/DS339/AB/R, WT/ DS340/AB/R, WT/DS342/AB/R e Relatório do Painel em China: Measures Affecting Imports of Automobile Parts, WT/DS339/R, WT/DS340/R, WT/DS342/R. Disponível em: <https://www.wto. org/english/tratop_e/dispu_e/dispu_status_e.htm>. Acesso em: 11 jul. 2016. parágrafo 7.276, p. 221. 
misso, inclusive sob pena de multa se não o fizerem, apenas insumos estratégicos e ferramentaria adquiridos localmente dão condições ao fabricante de satisfazer a quantidade mínima de atividades fabris exigidas como requisito de habilitação no Inovar-Auto e posterior obtenção do crédito presumido do IPI.

Em suma, o Inovar-Auto exige que 80\% dos veículos fabricados no Brasil possuam uma quantidade mínima de ferramentas e insumos adquiridos no país, o que configura restrição quantitativa que favorece produtos locais em detrimentos dos similares estrangeiros, em ofensa à regra do tratamento nacional, como posta no $\mathbb{S}$ $5^{\circ}$ do art. III do GATT.

\section{Considerações finais}

A finalidade do presente artigo era analisar, com base na metodologia construída pela jurisprudência do sistema multilateral do comércio, cada um dos dispositivos do GATT que regulamentam os princípios do tratamento nacional e da nação mais favorecida que são invocados pela União Europeia e pelo Japão nos Painéis atualmente em curso contra os incentivos tributários brasileiros previstos no programa Inovar-Auto.

Nesse sentido, inicialmente, delimitou-se em que consiste e quais são os requisitos legais para a concessão das duas espécies de créditos presumido do IPI para os fabricantes de veículos instalados no Brasil, ou que aqui pretendam se instalar, bem como a redução do IPI na importação para aqueles mesmos contribuintes, que constituem os incentivos tributários previstos no Inovar-Auto.

Delimitados e explicitados os benefícios tributários brasileiros, o artigo primeiramente analisou os precedentes da OMC relativos a normas tributárias domésticas contestadas em face do princípio da nação mais favorecida, concluindo que o programa brasileiro ofende o princípio pelo fato de apenas produtores instalados no Mercosul e no México serem exonerados dos requisitos para a redução do IPI prevista no Inovar-Auto.

$\mathrm{O}$ artigo também constatou a inadequação do Inovar-Auto ao princípio do tratamento nacional com base nos testes de consistência construídos pela jurisprudência da OMC. Em tais hipóteses, foram analisados os três dispositivos do GATT que disciplinam o princípio e que foram apontados como violados pelo Japão e pela União Europeia. A aplicação dos testes desenvolvidos pela jurisprudência constatou que o programa brasileiro discrimina, indevidamente, o produto similar importado comparativamente ao localmente produzido.

A primeira regra que disciplina o princípio do tratamento nacional analisada foi o $₫ 2^{\circ}$, primeira sentença, do art. III do GATT, dispositivo que, de acordo com a jurisprudência pesquisada, é o mais invocado contra medidas tributárias domésticas que discriminam o produto importado em favor do produto localmente produzido. Nesse caso, o teste de consistência da jurisprudência da OMC demonstra que os produtos estrangeiros se sujeitam a um excesso de tributação indevido relativamente aos seus concorrentes domésticos privilegiados pelo Inovar-Auto.

A mesma ofensa ao princípio do tratamento nacional também foi verificada pela análise dos parágrafos $4^{\circ}$ e $5^{\circ}$ do art. III do GAT'T pela ótica jurisprudencial, já que reiteradamente o Inovar-Auto condiciona a concessão do crédito presumido do IPI à utilização de insumos produzidos no Brasil, além de exigir quantitativos mínimos de insumos nacionais no produto final aqui manufaturado, o que, reiteradamente, não admite os julgados da Organização.

A análise dos benefícios tributários do programa Inovar-Auto, procedida com a mesma metodologia aplicada pelo Órgão de Solução de Controvérsias, demonstra a provável procedência dos Painéis propostos contra o Brasil e, atualmente, em curso perante a OMC, o que imporá a imediata e urgente revisão, quiçá revogação, do Inovar-Auto. Tal provável desfecho terá impacto não apenas no programa Inovar-Auto, mas também na política de incentivos tributários adotada pelo Brasil que, muitas vezes, prima por, artificialmente, proteger a produção nacional em detrimento dos produtos importados, o que não admite o atual sistema multilateral do comércio.

\section{REFERÊNCIAS BIBLIOGRÁfICAS}

BOSSCHE, Peter Van den. The law and policy of the World Trade Organization. Text, cases and materials. Cambridge: Cambridge University Press, 2005.

JACKSON, J. H.; DAVEY, W. J.; SKYKES, A. J. Legal 
problems of international economic relations, cases, materials and text. 3. ed. Saint Paul: West Group, 1995.

JOHNSON, Jon R. The WTO Decision - MFN, National Treatment, TRIMS and Export Subsidies. In: IRISH, Maureen (Org.). The auto pact: investment, labour and the WTO. Haia: Kluewer Law International.

MATHIS, James H.; BHAGWATI, Jagdish. Regional trade agreements in the GATT/WTO. Cambridge: Cambridge University Press, 2002.

MAVROIDIS, Petros. Trade in goods. 2. ed. Oxford: Oxford University Press, 2012.

RUPEREZ, J. S. B. Non-fiscal discrimination in the WTO and EC Law: relations and solutions. The EC Tax Journal, v. 4, n. 2, p. 105-110, 2000.

SCHÖN, W. World Trade Organization law and tax law. IBFD Bulletin, Amsterdã, v. 58, n. 7, p. 283-296, 2004.

SHADIKHODJAEV, Sherzod. National Treatment on internal taxation: revisiting GATT Article III:2. Seoul: Korean Institute for International Economic Policy, 2008.

THIEL, Servas van; STEINBACH, Armin. The Effect of WTO Law in the legal order of the European Community: a Judicial protection deficit or a real-political solution, or both? In: LANG, Michael; HERDIN, Juditih; HOFBAUER, Ines (Org.). WTO and direct taxation. Haia: Kluwer Law International, 2005.

WTO. Final Act of the United Nations Conference on Trade and Employment. March 24, 1948. Disponível em: <http://www.wto.org/english/docs_e/legal_e/ havana_e.pdf $>$. Acesso em: 20 jul. 2014.

WTO. Dispute settlement. dispute DS472 Brazil: Certain Measures Concerning Taxation and Charges. Disponível em: <https://www.wto. org/english/ tratop_e/dispu_e/cases_e/ds472_e.htm>. Acesso em: 18 mar. 2015.

WTO. Final Act of the United Nations Conference on Trade and Employment. March 24, 1948. Disponível em: <http://www.wto.org/english/docs_e/legal_e/ havana_e.pdf $>$. Acesso em: 20 jul. 2014.

WTO. Relatório do Órgão de Apelação em Argentina: Measures Affecting the Export of Bovine Hides and the Import of Finished Leather, WT/DS155/R. Disponível em: <https://www.wto.org/english/tratop_e/ dispu_e/dispu_status_e.htm>. Acesso em: 11 jul. 2016. WTO. Relatório do Painel em Argentina: Measures Affectng the Importation of Goods, WT/DS438/R, W'T/ DS444/R, WT/DS445/R. Disponível em: <https:// www.wto.org/english/tratop_e/dispu_e/dispu_ status_e.htm>. Acesso em: 11 jul. 2016.

WTO. Relatório do Painel em Australia: Subsidies Provided to Producers and Exporters of Automotive Leather, WT/DS126/R. Disponível em: <https://www.wto. org/english/tratop_e/dispu_e/dispu_status_e.htm>. Acesso em: 11 jul. 2016.

WTO. Relatório do Painel em Income Tax Practices Maintained by Belgium, L/4424-23S/127. Disponível em: <https://www.wto.org/english/tratop_e/dispu_e/dispu_status_e.htm>. Acesso em: 11 jul. 2016.

WTO. Pedido de Consulta da União Europeia em Brazil: Certain Measures Concerning Taxation and Charges, WT/DS472/1, G/L/1061, G/SCM/D100/1, G/ TRIMS/D/39. Disponível em: <https://www.wto. org/english/tratop_e/dispu_e/dispu_status_e.htm>. Acesso em: 11 jul. 2016.

WTO. Relatório do Órgão de Apelação em Canada: Measures Affecting the Export of Civilian Aircraft, WT/ DS70/AB/R. Disponível em: <https://www.wto.org/ english/tratop_e/dispu_e/dispu_status_e.htm $>$. Acesso em: 11 jul. 2016.

WTO. Relatório do Órgão de Apelação em Canada: Certain Measures Affecting the Automotive Industry, WT/ DS139/AB/R, WT/DS142/AB/R e Relatório do Painel em Canada: Certain Measures Affecting the Automotive Industry, WT/DS139/R, WT/DS142/R. Disponível em: <https://www.wto.org/english/tratop_e/ dispu_e/dispu_status_e.htm>. Acesso em: 11 jul. 2016.

WTO. Relatório do Painel em Canada: Certain Measures Concerning Periodical, WT/DS31/R. Disponível em: <https://www.wto.org/english/tratop_e/dispu_e/dispu_status_e.htm>. Acesso em: 11 jul. 2016.

WTO. Relatório do Painel em Canada: Certain Measures Affecting the Renewable Energy Generation Sector; Canada: Measures Relating to the Feed-in Tariff Program, WT/DS412/R, WT/DS426/R. Disponível em: <https://www.wto.org/english/tratop_e/dispu_e/dispu_status_e.htm>.Acesso em: 11 jul. 2016.

WTO. Relatório do Painel em Canada: Measures Relating to Exports of Wheat and Treatment of Imported Grain, WT/DS276/R. Disponível em: <https://www.wto. org/english/tratop_e/dispu_e/dispu_status_e.htm>. 
Acesso em: 11 jul. 2016.

WTO. Relatório do Órgão de Apelaşão em China: Measures Affecting Imports of Automobile Parts, WT/DS339/ $\mathrm{AB} / \mathrm{R}, \mathrm{WT} / \mathrm{DS} 340 / \mathrm{AB} / \mathrm{R}, \mathrm{WT} / \mathrm{DS} 342 / \mathrm{AB} / \mathrm{R}$ e $\mathrm{R} e$ latório do Painel em China: Measures Affecting Imports of Automobile Parts, WT/DS339/R, WT/DS340/R, WT/DS342/R. Disponível em: <https://www.wto. org/english/tratop_e/dispu_e/dispu_status_e.htm >. Acesso em: 11 jul. 2016.

WTO. Relatório do Painel em China: Measures Related to the Exportation of Various Raw Materials, WT/ DS394/R WT/DS395/R WT/DS398/R. Disponível em: <https://www.wto.org/english/tratop_e/ dispu_e/dispu_status_e.htm>. Acesso em: 11 jul. 2016.

WTO. Relatório do Painel em China: Measures Affecting Tradign Rights and Distribution Services for Certain Publications and Audiovisual Entertainment Products, WT/DS363/R. Disponível em: <https://www.wto. org/english/tratop_e/dispu_e/dispu_status_e.htm>. Acesso em: 11 jul. 2016.

WTO. Relatório do Painel em Colombia: Indicative Prices and Restrictions on Ports of Entry, WT/DS366/R. Disponível em: <https://www.wto.org/english/tratop_e/ dispu_e/dispu_status_e.htm>. Acesso em: 11 jul. 2016.

WTO. Relatório do Órgão de Apelação em European Communities: Measures Affecting Asbestos and Asbestos-Containing Products, WT/DS135/AB/R. Disponível em: <https://www.wto.org/english/tratop_e/dispu_e/dispu_status_e.htm >. Acesso em: 11 jul. 2016.

WTO. Relatório do Painel de Apelação em European Communities: Customs Classification of Frozen Boneless Chicken Cuts, Complaint by Thailand, WT/DS286/R, WT/ DS269/AB/R, WT/DS286/AB/R. Disponível em: $<$ https://www.wto.org/english/tratop_e/dispu_e/dispu_status_e.htm>. Acesso em: 11 jul. 2016.

WTO. Relatório do Painel em EEC: Regulation on Imports of Parts and Components, L/6657, 37S/132. Disponível em: < https://www.wto.org/english/tratop_e/ dispu_e/dispu_status_e.htm>. Acesso em: 11 jul. 2016.

WTO. Relatório do Painel em Income Tax Practices Maintained by France, L/4423-23S/114. Disponível em: <https:// www.wto.org/english/tratop_e/dispu_e/dispu_ status_e.htm>. Acesso em: 11 jul. 2016.

WTO. Relatório do Painel em India: Measures Affecting the Automotive Sector, WT/DS146/R, WT/DS175/R. Di- sponível em: <https://www.wto.org/english/tratop_e/ dispu_e/dispu_status_e.htm>. Acesso em: 11 jul. 2016.

WTO. Relatório do Órgão de Apelação em India: Additional and Extra-Additional Duties on Imports from the United States, WT/DS360/AB/R. Disponível em: $<$ https://www.wto.org/english/tratop_e/dispu_e/dispu_status_e.htm>.Acesso em: 11 jul. 2016.

WTO. Relatório do Painel em Indonesia: Certain Measures Affecting the Automotive Industry, W'T/DS54/R, WT/ DS55/R, W'T/DS59/R, W'T/DS64/R. Disponível em: $<$ https://www.wto.org/english/tratop_e/dispu_e/dispu_status_e.htm>. Acesso em: 11 jul. 2016.

WTO. Relatório do Painel em Japan: Taxes on Alcoholic Beverages, WT/DS8/RT, WT/DS10/R, WT/ DS11/R. Disponível em: <https://www.wto.org/english/tratop_e/dispu_e/dispu_status_e.htm>. Acesso em: 11 jul. 2016.

WTO. Relatório do Órgão de Apelação em Japan: Taxes on Alcoholic Beverages, WT/DS8/AB/R, WT/DS10/ AB/R, WT/DS11/AB/R. Disponível em: <https:// www.wto.org/english/tratop_e/dispu_e/dispu_ status_e.htm>. Acesso em: 11 jul. 2016.

WTO. Relatório do Órgão de Apelação em Korea: Taxes on Alcoholic Beverages, WT/DS75/AB/R, WT/DS84/ AB/R. Disponível em: <https://www.wto.org/english/tratop_e/dispu_e/dispu_status_e.htm>. Acesso em: 11 jul. 2016.

WTO. Relatório do GATT em Japan: Trade in Semi-Conductors, L6309 -35S/116. Disponível em: <https:// www.wto.org/english/tratop_e/dispu_e/dispu_ status_e.htm>.Acesso em: 11 jul. 2016.

WTO. Relatório do Órgão de Apelação em Korean: Measures Affecting Imports of Fresh, Chilled and Frozen Beef, Various Measures on Beff, WT/DS161/AB/R/WT/ DS169/AB/R. Disponível em: <https://www.wto. org/english/tratop_e/dispu_e/dispu_status_e.htm>. Acesso em: 11 jul. 2016.

WTO. Relatório do Painel em Mexico: Tax Measures on Soft Drinks and Other Beverages, WT/DS308/R. Disponível em: <https://www.wto.org/english/tratop_e/ dispu_e/dispu_status_e.htm>. Acesso em: 11 jul. 2016.

WTO. Relatório do Painel em Income Tax Practices Maintained by the Netherlands, L/4425-23S/137. Disponivel em: $<$ https://www.wto.org/english/tratop_e/dispu_e/dispu_status_e.htm>. Acesso em: 11 jul. 2016. 
WTO. Relatório do Órgão de Apelação em Philippines: Taxes on Distilled Spirits, WT/DS396/AB/R, WT/DS403/ AB/R. Disponível em: <https://www.wto.org/english/tratop_e/dispu_e/dispu_status_e.htm $>$. Acesso em: 11 jul. 2016.

WTO. Relatório do Painel em Thailand: Customs and Fiscal Measures on Cigarettes from the Philippines, WT/ DS371/R. Disponível em: <https://www.wto.org/english/tratop_e/dispu_e/dispu_status_e.htm>. Acesso em: 11 jul. 2016.

WTO. Relatório do Painel em Turkey: Restrictions on Imports of Textiles and Clothing Products, WT/DS34/R. Disponível em: <https://www.wto.org/english/ tratop_e/dispu_e/dispu_status_e.htm>. Acesso em: 11 jul. 2016.

WTO. Relatório do Painel em United States Tax Legislation (DISC), BISD 23S/98, 28S/114. Disponível em: $<$ https://www.wto.org/english/tratop_e/dispu_e/dispu_status_e.htm>. Acesso em: 11 jul. 2016.

WTO. Relatório do Órgão de Apelação em United States: Tax Treatment for "Foreign Sales Corporations", WT/ DS108/AB/R e Relatório do Painel em United States: Tax Treatment for "Foreign Sales Corporations", WT/ DS108/R. Disponível em: <https://www.wto.org/english/tratop_e/dispu_e/dispu_status_e.htm>. Acesso em: 11 jul. 2016.

WTO. Relatório do Painel em United States: Measures Affecting Trade in Large Civil Aircraft - Second Complaint, WT/DS353/R. Disponível em: <https://www. wto.org/english/tratop_e/dispu_e/dispu_status_e. htm>. Acesso em: 11 jul. 2016.
WTO. Relatório do Painel em United States: Measures Affecting Alcoholic and Malt Beverages, DS23/R 39S/206. Disponível em: <https://www.wto.org/english/tratop_e/dispu_e/dispu_status_e.htm $>$. Acesso em: 11 jul. 2016.

WTO. Relatório do Painel em United States: Final Countervailing Duty Determination with respect to certain Softwood Lumber from Canada, WT/DS257/R. Disponível em: <https://www.wto.org/english/tratop_e/ dispu_e/dispu_status_e.htm>. Acesso em: 11 jul. 2016.

WTO. Relatório do Painel em United States: Section 337 of the Tariff Act of 1930, BISD 36S/345. Disponível em: <https://www.wto.org/english/tratop_e/dispu_e/dispu_status_e.htm >.Acesso em: 11 jul. 2016.

WTO. Relatório do Painel em United States Measures Affecting the Importation, Internal Sale and Use of Tobacco, BISD 41S/I/131. Disponível em: <https://www.wto.org/english/tratop_e/dispu_e/dispu_status_e.htm>. Acesso em: 11 jul. 2016.

WTO. Relatório do Órgão de Apelação em United States: Tax Treatment for "Foreign Sales Corporations", W T/ DS108/AB/RW e Relatório do Painel em United States: Tax Treatment for "Foreign Sales Corporation", WT/ DS108/RW. Disponível em: <https://www.wto.org/ english/tratop_e/dispu_e/dispu_status_e.htm>. Acesso em: 11 jul. 2016.

WTO. Relatório do Painel em United States: Subsidies on Upland Cotton, WT/DS267/R. Disponível em: $<$ https://www.wto.org/english/tratop_e/dispu_e/dispu_status_e.htm>.Acesso em: 11 jul. 2016. 
Para publicar na Revista de Direito Internacional, acesse o endereço eletrônico www.rdi.uniceub.br ou www.brazilianjournal.org.

Observe as normas de publicação, para facilitar e agilizar o trabalho de edição. 